\title{
1929-2009: 80 Anos de Cateterismo Cardíaco - uma História Dentro da História
}

\author{
Carlos A. M. Gottschall ${ }^{1}$
}

\section{RESUMO}

Neste artigo, o autor revisa os acontecimentos primordiais que originaram o cateterismo cardíaco, o surgimento do termo e os primeiros registros experimentais diretos da atividade cardíaca no final do século XIX. Ressalta as circunstâncias que cercaram a inauguração do cateterismo cardíaco no homem por Werner Forrsmann, há 80 anos, e depois sua introdução na medicina prática por Cournand, Richards e Baldwin, na década de 1940. Examina o desenvolvimento do cateterismo cardíaco direito e depois esquerdo, os acontecimentos que permitiram o desenvolvimento da angiocardiografia e a grande expansão das indicações do exame cardíaco por cateter, a partir da década de 1960. Mostra o desenvolvimento da ideia de angioplastia transluminal periférica e coronariana por Charles Dotter, enfatizando as figuras de Andreas Gruentzig e Richard Myler e as conquistas fundamentais, como os stents, que permitiram o extraordinário progresso desse procedimento, que tem dominado a cardiologia intervencionista. Aponta, a partir da visão de quem tem vivido grande parte dessa história, a importância do método para o desenvolvimento da cardiologia experimental, clínica e terapêutica nas últimas três décadas.

DESCRITORES: Cateterismo cardíaco/história. Angioplastia transluminal percutânea coronária/história. Cardiologia/ história.
P oucas inovações na história da medicina tiveram tanto impacto diagnóstico e terapêutico quanto o cateterismo cardíaco associado com angiocardiografia ${ }^{1}$. Não só pelo que representam nesses campos quanto pela correlação legitimadora - padrão-ouro de métodos não-invasivos, como eletrocardiografia,

\footnotetext{
1 Instituto de Cardiologia do Rio Grande do Sul/Fundação Universitária de Cardiologia - Porto Alegre, RS, Brasil.

Correspondência: Carlos A. M. Gottschall. Instituto de Cardiologia do Rio Grande do Sul - Unidade de Pesquisa - Av. Princesa Isabel, 370 - Santana - Porto Alegre, RS, Brasil - CEP 90620-001

E-mail: carlos.gottschall@cardiologia.org.br

Recebido em: 18/4/2009 • Aceito em: 8/6/2009
}

\section{ABSTRACT}

1929-2009: 80 Years of Cardiac Catheterization A History Within History

In this article, the author reviews the early steps of the cardiac catheterization, the development of this term and the first direct experimental records of the heart movements in the end of the $19^{\text {th }}$ century. The circumstances regarding the inauguration of cardiac catheterization in human beings by Werner Forrsmann eighty years ago and the application of the method in clinical medicine by Cournand, Richards and Baldwin between 1940 and 1950 are highlighted. The development of right and left cardiac catheterization, the facts that enabled the development of angiocardiography and the expansion of its indications after 1960 are reported. The author also reports how Charles Dotter created the concept of peripheral and coronary transluminal angioplasty and magnifies the contributions of Andreas Gruentzig and Richard Myler, as well as fundamental achievements such as stents, which led to an extraordinary improvement of this procedure which has been the basis of interventional cardiology. Based on the point of view of one who has experienced a major part of this history, he points out the importance of this method for the development of the experimental, clinical and therapeutical cardiology in the last three decades.

DESCRIPTORS: Heart catheterization/history. Angioplasty, transluminal, percutaneous coronary/history. Cardiology/ history.

ergometria, ecocardiografia, Doppler, medicina nuclear, monitorização à beira do leito, cintilografia, ressonância magnética, tomografia multislice e mesmo clínica.

A abordagem direta do coração e vasos para diagnóstico e tratamento por via percutânea evoluiu a partir de imagem produzida por radiação ionizante, isto é, raios X, descobertos por Wilhelm Konrad Roentgen, em 1895, e tubos capazes de atingir essas estruturas, isto é, cateteres. Cateteres diagnósticos visam três propósitos principais: medir variáveis hemodinâmicas cardíacas e vasculares; recolher amostras de sangue para análise; e injetar contraste intravascular. Cateteres terapêuticos servem para injetar fluidos ou drogas, dilatar vasos ou fechar defeitos com disposi- 
tivos adicionados a eles, e liberar objeto estranho nos vasos, por exemplo stent. Desenvolvimento nas técnicas de obtenção de imagem, de fármacos e na forma e potencialidades dos cateteres tem respondido pelo aperfeiçoamento dos resultados obtidos pela cardiologia intervencionista.

\section{Primórdios do cateterismo cardíaco}

A ideia de cateterizar o coração não nasceu de qualquer desejo diagnóstico, mas para esclarecer uma dúvida que atormentava os fisiologistas do século XIX. Antoine-Laurent Lavoisier, o maior gênio da ciência do século anterior, e de muitos séculos, estabeleceu as bases do processo respiratório que, semelhante à combustão dos corpos, absorve oxigênio pelos pulmões para produzir energia, os quais depois eliminam o produto de desgaste, bióxido de carbono. Mas o genial Lavoisier cometeu o erro de pensar que $\mathrm{O}_{2}$ surgiria por oxidação direta do carbono nos pulmões, de onde se distribuiria o calor corporal ${ }^{2}$. No começo do século XIX, o abade Lazaro Spallanzani demonstrou que mesmo seres inferiores absorvem oxigênio e eliminam gás carbônico e, em 1837, Heinrich Gustav Magnus, um professor de Física em Berlim, provou que o sangue arterial contém mais oxigênio e menos gás carbônico que o venoso, sugerindo que a diferença arteriovenosa de oxigênio indicaria fazer-se a respiração na periferia do organismo ${ }^{2}$.

Apesar disso, na segunda metade do século XIX ainda persistia a interrogação sobre se seria o pulmão a sede da respiração corporal e, assim, o órgão mais quente do corpo. Outro genial francês, Claude Bernard ${ }^{3,4}$, o pai da fisiologia experimental, quis verificar. Supôs que, se as temperaturas no ventrículo direito e no esquerdo fossem iguais à temperatura orgânica, esta não poderia ser gerada primariamente no pulmão. Bernard desenvolveu e colocou longos cateteres de chumbo (termômetros) preformados para medir diretamente a temperatura no interior dos ventrículos de cavalo, através da veia jugular e da artéria carótida. Como a temperatura no ventrículo direito foi discretamente mais alta, concluiu, em 1876, que Lavoisier errara o local da combustão orgânica e que o calor corporal deviase ao metabolismo celular nos diversos tecidos. Dessa forma, a expressão "cateterismo cardíaco", cunhada por Claude Bernard, nasceu da investigação da origem do calor animal ${ }^{3}$.

Revelação inquestionável só existe no mito e na religião. Na verdade, todo conhecimento resulta de uma evolução. Assim é que a ideia de colocar tubos em vasos já fora materializada antes em várias oportunidades. No século XVIII, Stephen Hales medira a pressão arterial de cavalos pela ascensão da coluna sanguínea em tubos colocados em suas carótidas e jugulares ${ }^{2}$. Em 1861, dois franceses 5,6 , o veterinário Jean-Baptiste Auguste Chauveau (1827-1917), interessado na sequência dos eventos e nos sons cardíacos, e o médico
Etiene-Jules Marey (1830-1904), que já havia registrado ondas de pressão arterial com o seu esfigmógrafo, começaram a investigar afirmações de William Harvey de que o ictus cordis começava com a sístole. Utilizando material modificado por eles, inseriram dois longos tubos no coração de um cavalo acordado e descreveram as curvas de pressão obtidas. Publicaram assim o trabalho inaugural que relata medidas simultâneas de pressão atrial e ventricular direitas e de aorta e ventrículo esquerdo por meio do uso de cateteres e demonstraram que a sístole ventricular e o batimento apical cardíaco começam e terminam simultaneamente. São também os primeiros a referirem-se à fase isométrica da contração cardíaca. Claude Bernard reconheceu a inocuidade do método, pouco afetando o animal, e pagou tributo aos dois inventores, enaltecendo seus admiráveis talentos, demonstrados pela impressionante qualidade das curvas obtidas, que supera todas as tentativas anteriores e algumas atuais.

Marey quase criou a cinecardiografia ${ }^{7}$. Interessado no estudo da locomoção animal em terra e no ar, após 1890 desenvolveu métodos cinematográficos para registrá-la, os quais depois foram aproveitados pelos irmãos Lumière para a invenção do cinema. Já em 1882 construíra seu "canhão fotográfico" capaz de documentar movimento. Essa ideia remonta ao astrônomo Pierre-Jules Janssen, que registrou, em 1874, 17 fotos em sequência da passagem de Vênus sobre o Sol. Marey conseguiu 24 figuras/segundo do voo das aves e aumentou a velocidade de exposição para 1/400 por segundo. Também inventou um cardiômetro ("tambor" de Marey), dispositivo capaz de registrar instantaneamente o volume cardíaco em coração funcionante, princípio depois aplicado por Starling em seus famosos estudos.

\section{Werner Forssmann}

Tamanho foi o impacto das invenções de Chauveau e Marey $^{5,6}$ - permitindo não só eternizar registros mas principalmente estudar detalhes até então desconhecidos da atividade cardíaca -, que ficaram para sempre retidas na memória de um jovem médico alemão. Muitos anos depois o inquieto e ousado Werner Forssmann ${ }^{8}$ inconformava-se com a precariedade dos métodos semiológicos de uma época, contando praticamente apenas com verificação do pulso, estetoscópio, eletrocardiografia e radiologia incipientes, cujos diagnósticos proporcionados eram quase sempre contrariados pelo resultado das necropsias. Depois confessaria em suas memórias, Experiments on Myself. Memoirs of a Surgeon in Germany ${ }^{8}$, que a inspiração para a invenção do cateterismo cardíaco no homem saiu do trabalho de Marey: "Como estudante, vi a reprodução de uma antiga gravura num livro de fisiologia. Originou-se de um trabalho de Marey que mostrava tocante, ingênua apresentação de um homem parado diante de um cavalo e segurando um tubo que havia sido introduzido pela veia jugular no coração do animal. O lúmen 
do tubo era fechado por uma borracha, que, dentro do ventrículo, transmitia as modificações pressóricas para um tambor de Marey e, consequentemente, para uma pena que desenhava as curvas de pressão. Essa figura excitou-me em tal grau que me perseguia dia e noite. Mesmo hoje eu a vejo exatamente quando fecho os olhos. As palavras desses clássicos fisiologistas franceses convenceram-me de que seus estudos experimentais podiam ser aplicados sem perigo no homem".

Não obstante a beleza dos propósitos enunciados acima, a motivação imediata de Forssmann foi encontrar "uma maneira satisfatória para injeção intracardíaca de droga", a fim de salvar pacientes desenganados e, ao mesmo tempo, mostrar que a injeção intracardíaca não causava pneumotórax, tamponamento ou laceração coronariana, nem que a entrada de qualquer objeto no coração seria fatal, como era pensado até surgirem Chauveau e Marey. Aos 25 anos, em 1929, na primeira oportunidade apresentou a ideia de cateterizar o coração ao seu chefe e confidente, Professor Richard Schneider, que, num misto de apoio e sarcasmo, achoua excelente, mas temerária, e sugeriu mais experimentação animal, mas o impetuoso Forssmann julgou desnecessário, já que havia treinado a inserção de cateteres uretrais em ventrículos direitos de cadáveres, o que comprovava por autopsias.

Resolveu agir por conta própria e, depois de uma experiência em que um colega desistiu de continuar enfiando um cateter até seu coração via veia basílica, persuadiu a enfermeira Gerda Ditzen da oportunidade de investigar o coração por cateter. Conquistou sua confiança (também seu coração?) a ponto de esta lhe fornecer material de venossecção sob seu controle e de oferecer-se como primeira paciente, apesar de Forssmann estar disposto a realizar o procedimento em si mesmo. Forssmann fingiu aceitar, amarrou-a à mesa cirúrgica para que não atrapalhasse, a seguir anestesiou sua própria fossa antecubital esquerda e inseriu na veia braquial um cateter uretral de 65 centímetros. Só depois desamarrou Gerda e pediu-lhe que chamasse a enfermeira encarregada dos raios $X$. Continuaram na sala de radiologia alguns degraus abaixo, quando Forssmann, colocado por trás do fluoroscópio, controlava em um espelho segurado por Gerda a progressão por ele mesmo do cateter até seu coração. Apesar de, pela distância, ter calculado que o cateter atingira o ventrículo direito, a radiografia da ocasião mostra que não passou da aurícula.

Conta Forrsmann que a notícia se espalhou como um raio pelo hospital e que quiseram arrancar-lhe o cateter do braço. Entretanto, versão menos romântica de um colega ${ }^{9}$, que deve ser recebida com cautela, revela possível tentativa de suicídio não negada por Forrsmann, já que, de caráter introspectivo, solitário e esquivo, teria sido encontrado pálido e imóvel em seu quarto, sentado sobre lençóis ensanguentados, com o cateter inserido na veia, até ser socorrido.
Quando viu a radiografia, Schneider congratulou-o, mas informou que o hospital em Eberswalde era pequeno demais para prosseguir com tão ousado plano, disse-Ihe que não falasse a ninguém antes de publicar seus resultados e aconselhou-o a iniciar treinamento fora. No entanto, antes de Forssmann partir, o procedimento foi usado para tratar um paciente morrendo de peritonite, fato que provou ser possível administrar medicamentos dentro do coração. Assim, o primeiro uso do cateterismo cardíaco foi terapêutico! Na ocasião, Forssmann expôs a um visitante, dr. Wilhelm His, descobridor do feixe de His, planos futuros de registrar atividade elétrica intracardíaca, no que foi desencorajado por este como inviável. O Professor Schneider recomendou-o a Ferdinand Sauerbach, diretor da clínica cirúrgica da Universidade de Berlim, onde foi aceito como assistente de cirurgia no principal hospital, o Charite.

Lá chegando, depois de apenas nove meses de graduar-se em Medicina, logo publicou, em 5 de novembro de 1929, no Klinische Wochenschrift, o artigo fundador ${ }^{10}$ do cateterismo cardíaco humano "Die Sondierung des rechten Herzens", que foi recebido com muito mais entusiasmo pela imprensa leiga que pelos colegas e o chefe. Continua contando Forssmann ${ }^{8}$ : em vez de cumprimentado, foi severamente repreendido por Sauerbach por ter publicado o trabalho sem seu nome nem o da clínica e de ser acusado em carta por Unger, um dos mais estimados cirurgiões do chefe, de furtar-lhe a prioridade da comunicação, e também de usurpador e plagiário por mais dois médicos de renome, Bleichroeder e Loeb, companheiros de Unger $^{8}$. Bleichroeder, em 1905, introduzira cateteres em artérias e veias de cães e nas suas próprias. Eles, em 1912, divulgaram experiências anteriores com mulheres, em que passavam cateteres através da artéria femoral até a bifurcação aórtica para administrar "Collargol" em casos de sepsis puerperal. Na verdade, Unger havia realizado dois procedimentos em Bleichroeder, um braquial e outro femoral, sem atingir o lado direito do coração. Num desses, Bleichroeder sentiu intensa dor precordial, mas, para evitar críticas, não mencionaram no artigo e nunca documentaram experimentos com radiografia ${ }^{11}$.

As ponderações de Forssmann de que havia um grande futuro terapêutico e investigativo para o cateterismo cardíaco, de que o trabalho não fora feito lá e de que serviria para sua habilitação ao início da carreira acadêmica (uma espécie de disssertação de mestrado) mais enfureceram o Geheimrat, que retrucou acusando-o de falta de definição entre ser cirurgião ou internista, já que o artigo interessaria no máximo a algum internista ou fisiologista e a nenhum cirurgião e que Forssmann deveria decidir o que queria ser. Quando este apontou ter apenas nove meses de formado, portanto ainda indefinido quanto à especialidade a seguir, foi sumariamente demitido por Sauerbach, 
que o acusou de ter ideias boas para usar num circo e não num hospital.

No desenvolvimento de qualquer atividade, a revelação da verdade geralmente é uma questão de momento histórico, porém também depende do acaso, da iniciativa pessoal e da receptividade do meio. O experimento em que Werner Forssmann cateterizou seu próprio coração revela determinação científica, mas também intrigas, decepção e controvérsias. Com a fixação dos predestinados, sem se abalar, Forssmann seguiu em frente, fazendo novas tentativas de autocateterizar-se e injetar contraste no coração. Pouco depois estava tratando de opacificar as cavidades cardíacas de coelhos e a seguir de cachorros, para "melhorar o diagnóstico cardíaco". Como o hospital não dispunha de biotério, acomodava os animais no apartamento de sua mãe e os transportava para as experiências, já parcialmente anestesiados. Lá injetava contraste no ventrículo direito e radiografava. O problema maior foi a afeição da mãe e da avó aos animais, as quais depois não queriam devolvê-los para novos estudos ${ }^{8}$.

O início do século XX constituiu uma época romântica, gloriosa e heroica da Medicina. Como protocolos de pesquisa não eram habituais, as experiências faziam-se por tentativa, erro e correções no decorrer dos procedimentos, além de os pesquisadores frequentemente serem objetos de suas pesquisas, autoinocularem-se agentes de doenças para melhor estudarem-nas, testarem medicamentos e métodos em si próprios, como foi o caso de Forssmann. Assim é que na próxima etapa tentou radiografar o coração injetando contraste iodado em si mesmo, não sem antes deixá-lo em longo contato com a própria mucosa bucal. Não percebendo reação maior seguiu em frente. Mesmo sem as radiografias mostrarem boa qualidade, apresentou seus resultados num congresso de cirurgia em 1931, onde baixaram seu tempo de apresentação de oito para quatro minutos. Os presentes mostraram-se desinteressados e sarcásticos, até que seu tio, um médico rural, consolou-o: "Não se entristeça. Estes idiotas não compreendem o que você tem na cabeça. Um dia você ganhará o Prêmio Nobel".

Embora tivesse continuado a investigar técnicas de cateterismo, como vimos, incluindo tentativas de angiocardiografia em si mesmo e em cães, não conseguiu quebrar a resistência aos seus esforços. Decepcionado, trocou de especialidade, passando para a Urologia, a seguir atuou como cirurgião militar do exército alemão na 2a Guerra Mundial e finalmente passou a exercer a Medicina como médico do interior. Desde 1931 nunca mais falou ou escreveu sobre cardiologia.

Depois de Forssmann cateterizar seu próprio coração transcorreu uma década para vencerem-se preconceitos, medos e dificuldades técnicas até o método ser aceito e assumido, capaz de gerar pesquisas nos Estados Unidos. O trabalho de Forssmann continuou praticamente esquecido na Europa até o fim da 2a Guerra Mundial. Depois, colegas ingleses e alemães passaram a prestigiá-lo com convites e promoções, que relutantemente aceitava, honestamente confessando-se desatualizado. Talvez tentando entender melhor o bicho homem, nos anos subsequentes dedicou-se a questões éticas, confessando-se um "líder fóssil" diante do progresso e de atitudes que não aprovava. A verdade é que o estudo da vida de Forrsmann o revela como portador daquela excentricidade indispensável para levar os gênios a realizações acima do comum dos homens.

Em 1956, juntamente com Cournand e Richards, sem ser formalmente um cientista, mas sim um arrojado desbravador, Forssmann foi contemplado com o Prêmio Nobel de Medicina, devido ao seu pioneirismo em cateterismo cardíaco. Faleceu em 1979, após sofrer dois infartos. Sua vida nos ensina muito: primeiro, que não há ideia totalmente isolada, pois toda ideia provém de uma anterior; segundo, que o degrau inicial de uma ideia realmente nova é quase sempre o desprezo de quem não a teve; e terceiro, que vale a pena perseverar quando se tem a sensação de estar certo.

\section{Cateterismo cardíaco direito}

Grandes ideias são seminais e dão frutos no devido tempo. A aplicação do cateterismo na Medicina humana começou lentamente pelo lado direito da circulação. Meses após a publicação do trabalho inaugural de Forssmann, Otto Klein ${ }^{12}$, em Praga, em 1930, realizou 18 medidas diretas do débito cardíaco no homem utilizando o método de Fick $^{2}$. No artigo publicado menciona a técnica como simples, sem complicações, e que isso foi possível graças a Forssmann.

A popularização do cateterismo deveu-se aos companheiros de Prêmio Nobel de Forssmann. Em 1932, o americano Dickinson Richards, grande clínico, humanista e líder entusiasta, do Columbia Presbyterian Medical Center, e o francês André Cournand, apaixonado por ciência e precisão, do Bellevue Hospital, em Nova York, nos Estados Unidos, iniciaram estudos que se tornariam clássicos em função cardiopulmonar. Só em 1936, julgaram imprescindível o cateterismo das cavidades direitas e, em 1940, tentaram cateterizar um paciente, porém o cateter trancou em sua axila. O cateter de Cournand continuava sendo uma sonda urológica de borracha, medindo um metro, acrescida de uma curvatura na ponta e alguma radiopacidade.

Em 1941, Cournand e Ranges ${ }^{13}$ publicaram o trabalho inicial da aplicação clínica do cateterismo cardíaco no homem. Em termos de hoje é um trabalho simples, que estabelece valores hemodinâmicos normais do átrio direito, mas que na época despertou curiosidade sobre o cateterismo, estabeleceu condições para sua realização, mostrou sua inocuidade, foi aceito sem resistência para finalidades científicas e 
diagnósticas e ressaltou a potencial aplicação em diversas situações que se seguiram, como estudos fisiológicos com medida do débito cardíaco pelo princípio de Fick na doença hipertensiva, no choque e na doença pulmonar crônica. Todos continuavam empregando o famoso cateter de Cournand, cujo formato básico é usado até hoje para cateterismo direito e foi usado por Zimmerman et al. ${ }^{14}$, em 1949, e por outros, até 1960, para cateterismo esquerdo.

O ventrículo direito foi penetrado apenas em $1942^{15}$ e a artéria pulmonar, em $1944^{16}$. Dois anos por um caminho que hoje um estagiário de hemodinâmica percorre em minutos. Aqui recordo histórias contadas pelo Professor Mario Rigatto - que no início de sua carreira, lá por 1956-1958, teve o privilégio de conviver com André Cournand no Presbyterian Hospital, em Nova York -, sobre a preocupação do velho mestre cada vez que o cateter provocava uma extrassístole ao contatar o átrio direito! É bom lembrar que o desfibrilador não existia. Mas a partir daí abria-se o caminho para a moderna hemodinâmica. Tornava-se possível medir pressões e colher amostra de gases do sangue da aurícula direita, ventrículo direito e artéria pulmonar. Fizeram-se análises de diferentes tipos de choque e seus tratamentos, bem como se estudou a fisiopatologia da insuficiência cardíaca, cardiopatias hipertensiva, reumática e cor pulmonale ${ }^{15}$. Foi realizado estudo dos efeitos da digoxina intravenosa, sendo assim inaugurada a investigação da ação de drogas por meio do cateterismo ${ }^{17}$. Outros expandiram o uso do cateterismo venoso $^{18}$ para o rim e o fígado ${ }^{19}$. Baldwin et al. ${ }^{16} \mathrm{e}$ Brannon et al. ${ }^{20}$ apresentaram os primeiros registros de diagnóstico de comunicação interventricular e comunicação interatrial por cateter, respectivamente.

Tão marcante foi a influência de Cournand, Richards e Eleanor Baldwin sobre o desenvolvimento da fisiopatologia cardiorrespiratória ${ }^{21,22}$ nas décadas de 1940 e 1950, que os estudos das funções pulmonar e cardíaca se faziam juntos e os locais onde ocorriam passaram a chamar-se Laboratório Cardiopulmonar, o qual misturava salas de hemodinâmica com espirômetros de campânula, gasômetros de Tissot, oxímetros, analisadores de gases. Foi a época áurea dos estudos metodológicos sobre ventilação, difusão e perfusão pulmonares, cujos conceitos desde então se tornaram interdependentes. Nunca será suficientemente ressaltada a contribuição desses pesquisadores para o entendimento da fisiopatologia das doenças cardiopulmonares.

É certo que o aparecimento da cirurgia cardíaca ${ }^{23}$ por volta de 1940, principalmente por Blalock, Gross e Crawford, estimulou o detalhado estudo anatômico e fisiopatológico de pacientes com cardiopatias congênitas e adquiridas, considerando-se especialmente curto-circuitos, hipertensão pulmonar e cianose. Os estudos de Dexter et al. ${ }^{24}$ em cardiopatias congênitas, em 1947, fixaram as bases atuais do diagnóstico de curto-circuitos por gasometria arterial. De enorme importância revestiu-se a descoberta por Dexter de que encravando a ponta do cateter na periferia da circulação pulmonar pode-se medir e registrar a "pressão capilar pulmonar", a qual reflete retrogradamente pressão venocapilar e atrial esquerda e, por inferência, a pressão diastólica final do ventrículo esquerdo. Sem essa pioneira verificação, o cateter de Swan-Ganz ${ }^{25}$, depois, não teria tanta utilidade. Em 1948, pesquisadores inspirados por Cournand, Lewis Dexter e Richard Bing $^{7,26}$ encontraram fórmulas derivadas do conteúdo sanguíneo em oxigênio para determinar, por meio de resultados oximétricos, fluxo sanguíneo regional, fluxo efetivo pulmonar, direção e intensidade de curtoscircuitos, resistências vasculares pulmonares e sistêmicas, todas medidas de enorme utilidade fisiológica, clínica e cirúrgica. Registros de curvas pressóricas e oximetria de cavidades cardíacas direitas, artéria e capilar pulmonares tornaram-se rotina, mostrando peculiares e definidos padrões diagnósticos de muitas cardiopatias congênitas e adquiridas ${ }^{27}$.

Por alguns erros fortuitos nos primeiros cateterismos, o cateter, em vez de ser dirigido ao ventrículo direito, caía inadvertidamente no seio venoso no átrio direito e o sangue aspirado vinha muito escuro, até que alguns examinadores perceberam e trocaram os errados diagnósticos de exagerada dessaturação sanguínea ventricular pela oportunidade de estudar o metabolismo miocárdico ${ }^{7,28}$. Nasceu assim frutífero campo de estudos fisiológicos sobre o coração. Um dos primeiros achados por Bing et al. ${ }^{28}$ apontou que em jejum o coração extrai energia preferentemente de ácidos graxos, mas pode utilizar aminoácidos e cetonas. Cateterismo cardíaco tornou-se imprescindível para estudar metabolicamente o coração ${ }^{29}$.

O advento da 2a Guerra Mundial fez desenvolver plásticos que logo suplantaram os velhos cateteres de borracha ou náilon e os avanços da eletrônica aposentaram os ultrapassados registradores mecânicos. Novos tubos de raios catódicos aperfeiçoaram os apareIhos de raios $\mathrm{X}$ e tornaram possível a televisão. Para efeitos práticos, o cateterismo cardíaco continuou a ser realizado apenas do lado direito do coração até cerca de 1950. Entretanto, a década de 1940-1950 foi tão profícua que, a não ser pelo aperfeiçoamento do material, tudo o que se faz hoje em cateterismo direito é essencialmente o mesmo que se fazia então.

\section{Cateterismo cardíaco esquerdo}

A primeira tentativa registrada de entrar no ventrículo esquerdo para fins médicos foi em 1831, quando Johann Dieffenbach tentou cateterizar o ventrículo esquerdo pela artéria braquial, para sangrar um paciente com cólera. Provavelmente não conseguiu, pois não obteve o sangue desejado ${ }^{30}$. Como já visto, em 1929, impulsionado por vários estímulos e por profunda intuição, Werner Forssmann iniciou o cateterismo cardíaco. Bleichroeder, Unger e Loeb ${ }^{11}$, depois, 
em 1930, administraram drogas, com sucesso, por meio de cateterismo aórtico. Nas duas décadas seguintes, muitas infrutíferas tentativas de opacificar por contraste coração e vasos a partir dos lados direito e esquerdo ${ }^{31-37}$ da circulação limitaram-se principalmente por inaptidão da tecnologia radiológica.

Por volta da década de 1940, vários grupos entraram na aorta medindo pressões e realizando arteriografia ${ }^{33-37}$. Ingraham et al. ${ }^{38}$, em 1947, trocaram os primitivos tubos de borracha por cateteres de polietileno, usados por Pierce ${ }^{39}$ e Seldinger ${ }^{40}$ e cuja maior vantagem é um lúmen mais largo em relação à parede e maior flexibilidade. A pouca radiopacidade foi uma desvantagem inicial, corrigida por Odman ${ }^{41}$, em 1956, depois de tentativas pouco efetivas por outros. Avanços posteriores incluíram náilon, dácron, teflon, poliuretano e metal nos cateteres.

Depois dos progressos entre 1940-1950, o grande avanço foi protagonizado por Zimmerman et al. ${ }^{14}$ e Limón Lason et al. ${ }^{42}$, em 1950, ao introduzirem o cateterismo retrógrado do ventrículo esquerdo, permitindo que os dois lados do coração fossem examinados, o que não ocorria até então. Outras tentativas para penetrar no lado esquerdo do coração geralmente foram grosseiras, inefetivas e de grande risco para o paciente, incluindo métodos como punção paraesternal ${ }^{43}$, punção subxifóidea ${ }^{43-45}$, punção apical ${ }^{46}$, punção auricular esquerda supraesternal ${ }^{47,48}$, punção auricular esquerda transbrônquica ${ }^{49,50}$, punção auricular esquerda paravertebral|51, e punção atrial transeptal ${ }^{52}$.

Mesmo a técnica de Zimmerman et al. ${ }^{14}$, em seu início, foi difícil e originária de sérias complicações. Zimmerman usou um cateter Cournand $6 \mathrm{~F}$ conduzido sobre uma guia de Bing inserida por dissecação na artéria ulnar. O autor relatou a dificuldade de progredir o cateter contra o fluxo pressurizado e através da valva aórtica "no curto período de ejeção em que esta fica aberta". Conseguiu registros de pressões e de gradientes em 11 pacientes com insuficiência aórtica luética, mas no paciente com insuficiência aórtica reumática ocorreu fibrilação ventricular irreversível. Naquele tempo, os cateteres eram lubrificados com óleo de oliva esterilizado e cheios de solução salina heparinizada a $1 \%$. O frequente vasoespasmo impedia a reinserção do cateter, e na primeira série de Zimmerman houve impossibilidade de cruzar a junção aorto-subclávia em 20\% dos casos! Após o procedimento, a artéria era suturada e o paciente recebia $75 \mathrm{mg}$ de heparina intramuscular, a cada seis horas, por três dias.

Também em 1950, Limón Lason, Alvarez e Bouchard $^{42}$, no México, relataram a fácil entrada no ventrículo esquerdo de 17 pacientes por meio de um cateter com ponta em "J", mas o método não foi valorizado, provavelmente pela dificuldade que outros encontraram em cruzar a valva aórtica ou por ter sido escrito em espanhol. Por essa época, a cateterização arterial retrógrada transaxilar foi proposta por Pierce ${ }^{39}$, mas logo abandonada em vista de suas complicações. Tudo isso mostra quão difícil foi ultrapassar a barreira valvar para entrar no ventrículo esquerdo.

Penetrar no lado arterial da circulação antes de 1940 significava geralmente puncionar diretamente a aorta torácica ou abdominal, até que Fariñas ${ }^{34}$ entrou com um cateter retrogradamente dissecando a artéria femoral e estimulando outros a tentarem entrar pela braquial, radial, ulnar, dissecando-as e depois puncionando-as. Colocar cateter numa artéria requer ou exposição cirúrgica ou punção transcutânea desse vaso. Inacreditavelmente, o primeiro método era quase único até depois de 1950. Foi a facilitação da punção que consagrou em 1953 o sueco Sven Seldinger ${ }^{40}$, quando este descreveu nova técnica de cateterismo percutâneo pela punção da artéria femoral, a seguir introdução de uma guia flexível na artéria por dentro da agulha de punção, depois retirando a agulha e deixando a guia, e sobre a guia introduzindo retrogradamente um cateter na aorta, finalmente retirando a guia, permanecendo o cateter.

Embora outros $34,37,39$ tivessem introduzido cateteres por via percutânea no lado esquerdo da circulação, os métodos eram complicados perto da obviedade da técnica de Seldinger ${ }^{40}$, que abriu caminho para a rotinização do cateterismo cardíaco esquerdo e para a coronariografia. No entanto, a popularização da entrada no ventrículo esquerdo só ocorreu a partir de 1957, quando Prioton et al. ${ }^{53}$ modificaram levemente essa técnica, passando um cateter de polietileno sobre uma longa guia capaz de chegar até aquele ventrículo, para conduzir o cateter. É o que se faz até hoje.

O dr. Charles Dotter, um radiologista vascular de Oregon, Estados Unidos, em 1960, descreveu uma guia flexível com material de instrumento musical, que funcionou muito bem, e Dotter e Gensini ${ }^{54}$ logo depois realizaram angiografia visceral seletiva possibilitada por modificações nas extremidades dos cateteres. Mesmo já estando em uso o cateterismo retrógrado do ventrículo esquerdo, mas devido às dificuldades de cruzar a valva aórtica, em 1956, Brock et al. ${ }^{46}$ propuseram o cateterismo desse ventrículo por punção transapical, tendo obtido êxito com 23 pacientes. Outros confirmaram a validade do método, por incrível que pareça com poucas complicações. Pode ser usado até hoje, raramente, em pacientes selecionados, quando é impossível passar a valva aórtica, em pacientes com próteses valvulares e em pacientes com doença vascular periférica que impeça cateterismo retrógrado.

Em 1963, quando doutorando, iniciei-me em hemodinâmica no Laboratório Cardiopulmonar da Santa Casa de Porto Alegre, orientado por Mario Rigatto, que recém retornara de longo estágio com o Professor Alfred Fishman, em Nova York. Participei de algumas punções transparietais de ventrículo esquerdo, sem 
nenhuma complicação: o dr. Nilo Medeiros no registro, dois no cateterismo e outro olhando o scope do elecrocardiograma e gritando "V", "V", "V" cada vez que surgia uma extrassístole. Conseguia-se medir o gradiente, mas o procedimento terminava com os examinadores mais lívidos que o paciente! Sinceramente, hoje não teria coragem de repetir a façanha.

\section{Angiocardiografia}

A angiocardiografia tem se desenvolvido geralmente em paralelo com o cateterismo. Hoje em dia, cateterismo cardíaco e angiocardiografia são considerados procedimentos simples e acessíveis e os iniciantes na arte custam a imaginar as imensas dificuldades que representavam na década de 1930 . Continuaram sendo considerados métodos de exceção até a década de 1950.

Em 1927, Antonio Caetano de Abreu Freire, autocognominado Egas Moniz, em homenagem ao lendário herói português, publicou em Lisboa o trabalho pioneiro sobre angiografia cerebral ${ }^{55}$. Para visualizar a circulação, Moniz e colaboradores buscaram, com experiências in vitro, um contraste que opacificasse bem. Fixaram-se no iodeto de sódio. A partir daí o próximo problema a vencer foi o do equipamento radiológico inadequado, que começou a ser resolvido pelo radiologista José Pereira Caldas, inventor do "rádio-carrossel", um dispositivo operado manualmente, capaz de permitir a exposição de seis filmes em rápida sequência. Foi o embrião da ideia de cinerradiografia. A seguir, o grupo continuou testando contrastes, usou dióxido de tório (Torotrast) e, finalmente, compostos orgânicos iodados (Lipiodol) ${ }^{55}$. Em 1929 é que dos Santos et al. ${ }^{31}$, discípulos de Moniz, divulgaram técnicas de aortografia abdominal e arteriografia periférica e publicaram a primeira imagem da aorta opacificada por contraste injetado diretamente na região lombar. Na época, esses trabalhos seminais foram ignorados nos Estados Unidos, mas começaram a ser aceitos na Europa.

Estimulado pelas conquistas do cateterismo cardíaco até então, Castellanos e Pereira ${ }^{33}$, em Cuba, depois de experimentos em cachorros e cadáveres, divulgaram em 1937, e publicaram dois anos depois, o primeiro trabalho importante sobre angiocardiografia por injeção intravenosa (periférica) de contraste em crianças com comunicação interventricular e estenose pulmonar, por meio de rudimentar equipamento automático para angiocardiografia. Obtiveram imagens aproveitáveis. Em 1938, Robb e Steinberg ${ }^{32}$, da Universidade Harvard, nos Estados Unidos, visualizaram câmaras cardíacas de humanos adultos, também injetando contraste em veias periféricas. Surgia um trabalho seminal nesse campo.

Na época, a dificuldade para realizar angiocardiografia vinha do primitivismo dos contrastes, dos injetores para manter um bolus adequado e das filmagens para obter mais que uma imagem. O método usado por Robb e Steinberg consistia na injeção de suficiente quantidade de contraste no sangue venoso para opacificar coração e vasos na primeira circulação e radiografar essas estruturas no tempo da máxima opacificação. Para isso, depois de muitos testes em animais, usaram solução de Diodrast a 70\%, estabeleceram dosagem adequada, rápida injeção intravenosa, determinação precisa do tempo para exposição aos raios $X$ (um a dois segundos menos que o tempo de circulação braço-pulmão por éter e braço-seio carotídeo por cianido) e posição certa para radiografar. Conseguiam visualizar a circulação pulmonar e uma ou duas câmaras cardíacas em mais de $90 \%$ dos $\operatorname{casos}^{32}$ ! É impressionante a similaridade da concepção desse método com a moderna tomografia computadorizada multislice. Quando apresentaram os resultados num meeting da American Heart Association, em 1938, muitos presentes consideraram tratar-se de uma fraude.

Já no seu segundo volume, em 1949, páginas 417-424, os Arquivos Brasileiros de Cardiologia exibiam o trabalho "Angiocardiografia. Técnica e valor prático", assinado por Horácio Kneese de Melo e colaboradores, reconhecido como o artigo completo inaugural sobre essa matéria no Brasil, apontando, concomitantemente, que os professores José Job, Darci Ilha e outros haviam introduzido a técnica em 1948, em Porto Alegre, RS, Brasil.

No início da década de 1960, surgiram imagens em movimento, cineangiocardiografia, em vez da angiocardiografia sequencial em chapas radiológicas estáticas. Aperfeiçoaram-se os contrastes. Num período de dois anos adicionaram-se à segurança do exame práticas maneiras de massagem cardíaca e desfibriladores. Em 1960 foi demonstrado que massagem cardíaca com tórax fechado é tão efetiva quanto a céu aberto $^{56}$. A investigação hemodinâmica e angiográfica cardiovascular tornara-se segura como nunca antes. As técnicas fizeram-se mais simples e as fibrilações passaram a ser controladas pelo antigo desfibrilador de Zoll et al. ${ }^{57}$, introduzido em 1961, embora já em 1936 Ferris et al. ${ }^{58}$ e depois Wiggers ${ }^{59}$ tivessem descrito os efeitos da corrente elétrica sobre o coração. Em 1962, a facilidade de uso do desfibrilador de Lown et al. ${ }^{60}$ afastou o espectro das arritmias incontroláveis das salas de hemodinâmica.

$\mathrm{Na}$ era da angiocardiografia de rotina, depois de 1960, os cateteres de Cournand perderam prestígio para realizar cateterismo esquerdo porque seu furo terminal permitia rebote para fora do ventrículo durante a rápida injeção de contraste com alta pressão para filmar a ventriculografia, e o jato central causava muita arritmia e infiltração na parede ventricular. As contribuições de Odman ${ }^{41}$ e Olin ${ }^{30}$, em 1958, equiparam os cateteres com furos laterais e ponta curva mais flexível que o corpo do cateter ("pigtail"), para prevenir esses inconvenientes durante a ventriculografia. Littmann et al. ${ }^{61}$ demonstraram sua fácil passagem através da valva aórtica normal e Bellman et al. ${ }^{62}$ e Williams et al. ${ }^{63}$ 
usaram-no com êxito para angiografia aórtica e coronariana em humanos.

\section{Punção transeptal}

Com o desenvolvimento do cateterismo retrógrado do ventrículo esquerdo logo ficou evidente que não é fácil penetrar no átrio esquerdo por essa via, principalmente em casos de valvulopatia mitral. A punção transeptal de aurícula esquerda foi proposta separadamente em 1959 por Ross ${ }^{52}$, entrando a partir de dissecação da safena, e Cope ${ }^{64}$, entrando por punção percutânea, ambas com a vantagem de, por serem inteiramente interatriais, não provocarem as complicações de técnicas extravenosas, como hemopericárdio e laceração. Inicialmente foi realizada por dissecação de safena e inserção de uma bainha $11 \mathrm{~F}$ no átrio direito. Era então passada uma agulha até a ponta do cateter e ambos posicionados contra o septo. Após puncionar-se o septo, a pressão atrial podia ser registrada. Estendendo-se um tubo de polietileno através da agulha geralmente era possível chegar ao ventrículo esquerdo e registrar suas pressões.

Cope $^{64}$, em 1959, introduziu seu método de entrada seguido por múltiplas trocas de agulhas e cateteres, mas a técnica de Brockenbrough e Braunwald ${ }^{65}$, em que se coloca percutaneamente um cateter preformado no átrio direito através de uma guia e depois se avança uma agulha longa até a ponta do cateter, posicionando-a contra o septo e perfurando-o para dar passagem ao cateter, permanece praticamente intacta até hoje. Após completada a punção e documentada pela curva pressórica atrial esquerda, avança-se o cateter para o átrio esquerdo e retira-se a agulha. Bevegard et al. ${ }^{66}$ descreveram tentativas de punção septal atrial através da veia jugular externa, com sucesso, mas sem receptividade.

Após certo declínio do uso de técnicas de punção transeptal, esse método foi revitalizado, principalmente para tratamento da estenose mitral com valvuloplastia por balão, este a grande indicação atual de punção transeptal. Modificação da técnica por Mullins ${ }^{67}$, em 1979, permitiu a introdução de um cateter "pigtail" no átrio e no ventrículo esquerdo. Embora sejam reconhecidos todos os méritos de $\operatorname{Ross}^{52}$ ao introduzir a punção transeptal atrial na prática do cateterismo, conta-se que esse método não surgiu de uma genial inspiração sua, mas da sugestão de um estagiário sulamericano em seu laboratório, que lhe perguntou por que não entrava na aurícula esquerda pela aurícula direita, em vez de tentar uma perigosa e demorada punção transbrônquica. Ross pensou e viu que, como outros antes dele, não percebera o óbvio.

\section{Cateterismo à beira do leito}

A partir do puro estudo fisiológico o cateterismo estendeu-se para o campo diagnóstico à beira do leito. A necessidade de acompanhar pacientes clinica- mente críticos permitiu que Swan et al. ${ }^{25}$ desenvolvessem o cateter-balão fluxo-dirigido em 1970. Relatou Jeremy Swan que concebeu a brilhante ideia de aplicar cateterização cardíaca a pacientes sob cuidados intensivos, sem fluoroscopia, a partir da observação do giro das hélices dos navios. Primeiro imaginou, em 1967, uma espécie de guarda-chuva na ponta de um cateter a ser conduzido pela corrente sanguínea até a artéria pulmonar, sem sucesso. Depois se fixou num sofisticado cateter fino e flexível?

A materialização da ideia de um cateter navegador apoiou-se na ligação de Swan com um laboratório fabricante de válvulas cardíacas, permitindo-lhe utilizar a tecnologia para colocar um balão na ponta do cateter, a fim de ser levado pelo fluxo de sangue. A contribuição decisiva de William Ganz decorreu da incorporação da medida do débito cardíaco por termodiluição ao cateter e do impacto causado sobre os clínicos. Swan contou com o apoio de Ganz para fabricar o cateter multipotente e testar sua validade em determinar pressões pulmonares em animais. Surgiu assim, em 1970, o cateter de Swan-Ganz ${ }^{25}$, capaz de propiciar a medida de pressões em átrio e ventrículo direitos, artéria e capilar pulmonar e débito cardíaco por termodiluição. Emergia o cateterismo cardíaco na sua aplicação mais prática, imediata e salvadora, que hoje monitora milhões de enfermos no mundo. Por essa porta a hemodinâmica saiu da sala de cateterismo para a Unidade de Terapia Intensiva (UTI).

\section{Coronariografia}

Embora em 1931 Forssmann tenha mostrado ser possível injetar contraste dentro do coração, foi trilhado um longo caminho até a visualização das artérias coronárias, fato inaugurado pela escola sueca ${ }^{35-37,68}$. Em 1933, Rousthöi ${ }^{69}$ e Reboul e Racine ${ }^{43}$ descreveram a opacificação parcial das artérias coronárias após realizar aortografia ascendente respectivamente por punção arterial e por punção ventricular esquerda. No trabalho citado, Rousthöi ${ }^{69}$ mostrou coração de rato contrastado a partir de injeção na aorta via carótida direita, cunhou o termo "angiocardiografia" e concluiu que a técnica poderia ser aplicada no homem. Passando do rato para o homem, cinco anos depois Robb e Steinberg ${ }^{32}$ demonstraram que coração, vasos centrais e aorta podiam ser visualizados em filmes radiológicos a partir de injeção venosa periférica de contraste, e Castellanos e Pereira ${ }^{33}$, em 1939, obtiveram um aortograma injetando contraste via artéria braquial. Como visto, em 1941 Fariñas $^{34}$ foi o primeiro a descrever técnica para obter aortografia introduzindo cateter na artéria femoral, exposta cirurgicamente, até atingir a aorta. Em 1945, Radner ${ }^{35}$, na Suécia, utilizou a técnica de visualização de vasos cerebrais do português Egas Moniz para opacificar artérias coronárias. Radner perfurava o esterno e puncionava a aorta ascendente para, sob fluoroscopia, nela injetar contraste, o qual penetrava nas artérias coronárias. Em 1947, 
baseando-se nos estudos de Robb e Steinberg 32 , usou método menos traumático, conseguindo entrar com o cateter pela artéria radial até a aorta e injetar contraste perto das válvulas semilunares ${ }^{36}$.

Injeções não seletivas de contraste para visualizar as artérias coronárias ${ }^{70-72}$ continuaram até Sones ${ }^{73,74}$ introduzir sua técnica. Assim é que referências à coronariografia nas décadas de 1940 e 1950 contemplavam toscas imagens em chapas radiológicas estáticas, resultantes de injeções maciças de contraste em espaços limitados, geralmente aorta ascendente. Como visto, muitos pesquisadores ${ }^{35-37,43,68,70-72}$ antes de Sones tentaram e alguns conseguiram visualizar as artérias coronárias ou seu início por meio de cateterização retrógrada e injeção de contraste na raiz da aorta. Logo ficou claro que grandes quantidades de contraste causavam efeitos deletérios e borravam a imagem da aorta, impedindo a adequada visualização das artérias coronárias. Grande progresso tecnológico ocorreu em 1949, quando chapas radiográficas simples foram substituídas por cassetes automáticas que produziam cortes de imagens em série. Um ano depois surgia o intensificador de imagem, que permitiria o desenvolvimento - em filmagem contínua - da cineangiocardiografia, capaz de fornecer imagens mais nítidas com menor injeção de constraste e menor exposição aos raios $\mathrm{X}$.

Para melhorar a qualidade técnica dos documentos foram tentadas injeção fásica do contraste apenas durante a diástole ${ }^{71}$, várias formas de reduzir o débito cardíaco, como parada com acetilcolina, e elevação da pressão intrabrônquica. Dotter e Frische ${ }^{72}$ chegaram a introduzir um balão com dupla luz que ocluía a aorta acima da emergência das artérias coronárias por um breve período, a fim de limitar o escoamento periférico do contraste injetado. Bellman et al. ${ }^{62}$, em 1960, propuseram um cateter com ponta espiralada e furos laterais para dirigir o jato de contraste em direção às artérias coronárias, sem maiores resultados. A força do hábito é um condicionante terrível. É impressionante como tantos talentosos investigadores continuassem insistindo com punções diretas na aorta em vez de cateterizar uma artéria periférica.

Em 1958, na Cleveland Clinic, Mason Sones, um cardiologista pediátrico, testava novos métodos de cineangiocardiografia opacificando as artérias coronárias por meio da introdução de 20-25 ml de contraste no seio de Valsalva com um cateter $\mathrm{NIH}$, introduzido via dissecação da artéria braquial, usando um potente injetor. Na época havia a crença generalizada de que contraste direto nas artérias coronárias, um fluido sem oxigênio, era igual a arritmia fatal. Um dia, o cateter migrou para o óstio da artéria coronária direita precedendo a injeção e, antes que um Sones horrorizado pelo temor de fibrilação ou parada - gritando "nós o matamos" - pudesse interrompê-la, $40 \mathrm{ml}$ de contraste foram injetados diretamente dentro do vaso, tendo o paciente tolerado bem o acidente, a não ser por uma assistolia revertida por tossidas. Esse fato convenceu Sones da possibilidade de realizar coronariografia seletiva ${ }^{73,74}$, injetando contraste diretamente nas artérias coronárias, e com um volume dez vezes menor do que vinha sendo feito até então. Afortunadamente era uma dessas direitas que não produzem fibrilação facilmente. Se fosse, é possível que não tivéssemos coronariografia seletiva até hoje! Nesse ano Sones introduziu a angiografia coronariana, seguida pela cinecoronariografia, permitindo apreciar a dinâmica da circulação coronariana, de pontes de safena e mamárias em vez de imagens estáticas, usando cateteres preformados para cateterizar seletivamente o óstio das artérias coronárias sem ocluí-las, a fim de evitar fibrilação.

Entre $1959^{73}$ e $1962^{74}$ foram realizadas as primeiras mil coronariografias por dissecação braquial no laboratório de Sones, com apenas duas mortes e $2 \%$ de fibrilação ventricular. Mais do que por artigos em revistas científicas, o método de Sones foi popularizado por filme distribuído pelo Comitê de Educação Profissional da American Heart Association. A atitude de Sones de divulgar seu método em apenas quatro páginas em estilo simples - e somente depois de suficientemente testado - serve de lição para ávidos midiáticos atuais acostumados a pensar antes na manchete que no paciente. Um pouco de ética à antiga continua fazendo bem. Esse método conserva as características originais até hoje, permitindo que se realize também a ventriculografia pelo mesmo cateter. Considerando-se o membro superior, atualmente usa-se mais a punção braquial. A primeira coronariografia no Brasil foi realizada pela técnica de Sones por J. Eduardo Sousa et al. ${ }^{75}$, em 1966, no Instituto Dante Pazzanese de Cardiologia, em São Paulo.

Na década de 1960, radiologistas já usavam cateteres preformados para angiografia geral. Cateteres preformados, específicos para cada artéria coronária, e inserção por punção numa grande artéria, como a femoral, tornariam a coronariografia mais simples e generalizada. Por isso, arteriografia coronariana seletiva percutânea foi proposta em 1962 por Ricketts e Abrams $^{76}$, que introduziram cateteres preformados de polietileno, seguidos pelos de Judkins ${ }^{77}$ em 1967, estes construídos com material mais durável e de melhor torque, próprios para técnica femoral. Independentemente da via, a introdução dos métodos de Sones ${ }^{73,74}$ e de Judkins ${ }^{77}$ representou enorme avanço arquitetural ao simplificar a abordagem e permitir cateterizar os vasos coronarianos, respectivamente por via braquial e por via femoral.

Melvin Judkins fez sua grande contribuição depois de exercer urologia num hospital militar no Japão e cansar-se da vida de 10 anos como médico de família, resolvendo partir para uma residência em radiologia e depois para uma bolsa em radiologia cardiovascular, na Suécia. Interessante é que no início da 
década de 1960 Judkins foi aprender coronariografia com Sones, já que em seu hospital Starr requeria esse exame para todos os pacientes com mais de 50 anos que fossem colocar a válvula Starr-Edwards. As dificuldades com a técnica de Sones para cateterizar pacientes valvulares fizeram-no pensar em outro método. Dois cateteres preformados de tamanhos a escolher conforme o diâmetro aórtico, introduzidos por punção femoral e em sequência para artéria coronária esquerda e ramos e para artéria coronária direita e ramos e um de ponta enrolada que ele apelidou de "pigtail" ou "rabo de porco", para ventriculografia, tornaram a técnica de Judkins mais acessível para a maioria dos cardiologistas que a de Sones, esta mais dificultosa para aortas de grande calibre, além de requerer alguma habilidade cirúrgica no dissecar e suturar a artéria braquial.

Esses dois métodos impulsionaram extraordinário desenvolvimento de novos materiais e novos desenhos para a confecção de cateteres, capazes de atender às mais diversas preferências e necessidades. O desenvolvimento das técnicas e dos cateteres pouco teria adiantado se não fossem, como foram, acompanhados pelo aperfeiçoamento dos sistemas radiológicos, que, de uma simples placa pouco nítida, evoluíram do despertar e aperfeiçoamento da cineangiocardiografia $^{78}$ até a extraordinária resolução atual da angiografia digital, dos sistemas de registro que permitem estudos detalhados da função cardíaca e da fixação de uma equipe de trabalho no laboratório de cateterismo apta a enfrentar complicações usando equipamentos aperfeiçoados e sofisticados, como desfibriladores e suportes circulatórios ${ }^{79}$, principalmente para manter as condições hemodinâmicas de pacientes críticos submetidos a angioplastia coronariana.

Em 1970, Kattan demonstrou a utilidade da projeção axial para estudo contrastado do sistema arterial pulmonar $^{80}$. Em 1977, Bargeron et al. ${ }^{81}$ desenvolveram as projeções axiais para o estudo das cardiopatias congênitas, revolucionando a angiocardiografia, e Aldridge et al. ${ }^{22}$, no Canadá, já haviam introduzido projeções axiais para o estudo das artérias coronárias e idealizavam aparelhos de raios $\mathrm{X}$ com arcos em $U$ ou C, possibilitando melhor individualização de ramos coronarianos.

\section{Múltiplas aplicações do cateterismo cardíaco}

Dados diretos do cateterismo cardíaco são informações lineares que falam por si. Entretanto, a combinação de muitos deles permite criar medidas derivadas, como quantificação de fluxos, pressões e resistências. Importantes informações que podem ser obtidas a partir do cateterismo cardiovascular são: trajeto e posição do cateter; pressões intravasculares e intracavitárias; medidas de contratilidade miocárdica; medida do débito cardíaco; oximetria venosa e arterial; resistências vasculares; áreas valvulares; eletrocardiograma e fono intracavitários; angio e cineangiocardiografia; volumes cavitários; e aplicações terapêuticas. A inaugural e mais importante medida derivada do cateterismo cardíaco é a do débito cardíaco ${ }^{12}$ pelo método de Fick, com sua precisão matemática. Entretanto, é laborioso, demanda tempo. Para fins práticos tem sido substituído pela técnica de termodiluição descrita por Fegler ${ }^{83}$, em 1954. Curvas, pressões, oximetria, medidas funcionais e volumétricas tornaram-se rotina. Depois de 1950, uma das primeiras aplicações de medidas complexas obtidas pelo cateterismo cardíaco serviu para determinar áreas valvulares antes que fosse feita pela ecocardiografia. Em 1951, os Gorlin ${ }^{84}$, pai e filho, estabeleceram fórmulas calcadas em modelos hidráulicos e baseadas em registros de pressão e fluxo para calcular áreas valvulares mitral e aórtica, tornando mais precisas as indicações cirúrgicas para correção de suas disfunções.

Embora cateteres tenham sido usados antes para infundir substâncias ou embolizar vasos sangrantes ${ }^{30}$, a aplicação terapêutica do cateterismo cardíaco realizou-se pela primeira vez em 1966 por Rashkind e Miller ${ }^{85,86}$, quando usaram um cateter-balão para romper o septo interatrial de crianças com transposição dos grandes vasos, proporcionando assim melhor mistura sanguínea e tornando-se medida salvadora de recém-nascidos com essa e outras cardiopatias graves. Fazendo evoluir a técnica, em 1975, Park et al. ${ }^{87}$ introduziram a septostomia atrial por lâmina. Usam-se cateteres também para fechar canal arterial e defeitos septais atriais, para filtrar êmbolos na cava, para tratar bloqueio cardíaco com marcapasso, para prevenir fibrilação ventricular com desfibrilador permanente, e para administração de quimioterapia, outros medicamentos e antiarrítmicos.

Em 1968, foi iniciado no homem o estudo eletrofisiológico intracavitário do feixe de His por Sherlag et al. ${ }^{88}$, com desdobramentos diagnósticos e terapêuticos de grande importância, como tem sido o dos estudos eletrofisiológicos para tratamento de arritmias. Testes invasivos para taquicardias supra e ventriculares combinados com implante de marcapassos automáticos, eletrocirurgia e ablações mostram-se úteis clinicamente e reduzem a mortalidade dos pacientes tratados ${ }^{89}$.

Mudando conceitos no tratamento do infarto agudo do miocárdio, em 1976, Chazov et al. ${ }^{90}$, em Moscou, mostraram o valor de usar fibrinolíticos para tratar esse evento, mas demoraram a ser reconhecidos pelo mundo que só acredita no que é escrito em inglês. Em 1978, Rentrop et al. ${ }^{91}$ demonstraram que a simples perfuração do trombo com a guia ou com o cateter melhorava a evolução do infarto. Em 1979, em Gottingen, na Alemanha, Rentrop et al. ${ }^{92}$ evidenciaram a validade de usar estreptoquinase intracoronariana nas primeiras horas do infarto do miocárdio, causando a recanalização arterial por lise do trombo em cerca de $70 \%$ dos pacientes. A seguir, Meyer et al. ${ }^{93}$, 
em 1982, e Hartzler et al. ${ }^{94}$, em 1983, usaram cateteres-balão com ou sem injeção adicional de estreptoquinase, obtendo ótimos resultados no tratamento do infarto agudo.

Não obstante o balão para angioplastia coronariana introduzido em 1976 tenha evoluído a partir de um balão vascular periférico, foi no domínio das artérias coronárias que fez os mais espetaculares avanços, passando a retribuir a seu originário com o melhor do refinamento tecnológico. O menor calibre das artérias coronárias, suas tortuosidades e bifurcações, a possibilidade de afetar diretamente a função cardíaca com paradas e infartos, a necessidade do amparo da cirurgia cardíaca nos primeiros tempos e o grande significado médico, econômico e social da cardiopatia isquêmica colocaram no desenvolvimento dos sistemas de angioplastia coronariana enorme peso de pesquisa e ciência para fazê-los avançar, o que acabou alavancando progressos insubstituíveis em outros campos de intervenção por cateter.

A afirmativa acima pode ser exemplificada por outras possibilidades terapêuticas pelo cateterismo que vêm sendo utilizadas principalmente de 1980 para cá, além de tratamento de defeitos congênitos, fechamento de fístulas coronarianas e embolização septal, como é o caso das valvuloplastias - pulmonar ${ }^{95}$, aórtica ${ }^{96,97}$, mitral ${ }^{98-100}$ e tricúspide -, angioplastia de ramos pulmonares $^{101}$ e da aorta ${ }^{102,103}$, além de sistemas arteriais periféricos ${ }^{104,105}$. Como síntese de aperfeiçoamentos que não cessam, pode-se citar o sistema desenvolvido para tratamento de valvulopatia aórtica, o qual praticamente substitui todo o aparelho valvular por via percutânea ${ }^{106,107}$.

Assim é que o cateter tem passado pelas fases de apoio ao entendimento da fisiologia normal, da pesquisa fisiopatológica, de padrão-ouro para validar outros exames, até o estudo de drogas, sendo agora um instrumento predominantemente diagnóstico e intervencionista nas diversas cardiopatias. A angioplastia coronariana, pelo que envolve de progressos médicos e tecnológicos e pela extensão de sua aplicação, pode ser considerada o pico da pirâmide construída por todos esses avanços, já que beneficia e salva milhões de pessoas por ano em todo o mundo.

\section{Angioplastia coronariana}

A exemplo do que tantas vezes ocorre na medicina, o conceito de angioplastia surgiu por acaso. No início da década de 1960, Dotter viu regredir um estreitamento aterosclerótico numa artéria ilíaca pela passagem ocasional de um cateter diagnóstico. Dando seguimento à ideia de dilatação vascular, Dotter realizou experiências em cadáveres. Em 1964, junto com Melvin Judkins, realizou a primeira dilatação programada numa mulher de 82 anos com gangrena por obstrução da artéria poplítea, que havia recusado amputação e que se recuperou. Descrevendo o méto- do, em 1964, publicaram no Circulation $^{44}$ um artigo pioneiro sobre tratamento da obstrução arterial nas pernas de 11 pacientes, em que descreviam uma série de cateteres coaxiais passados sobre guia. Os cateteres ultrapassavam a região estenótica, sendo superpostos um sobre os outros e produziam dilatação sequencial (chamaram essa técnica de "angioplastia transluminal"), desobstruíam as artérias, a perfusão melhorava, a dor da isquemia cessava, e as lesões cutâneas cicatrizavam no pé doente, benefício que se manteve em muitos casos. Esse método representou a criação da ideia de angioplastia, entretanto cobrou um preço em termos de sangramentos (calibre do cateter), dissecções arteriais e tromboses e acabou abandonado. A técnica de Dotter fez mais sucesso na Europa que nos Estados Unidos, onde Dotter foi chamado de "crazy Charlie". Mas a ideia de dilatar artérias e depois especificamente coronárias permaneceu.

Entretanto, muitos investigadores europeus adotaram o método de Dotter e o desenvolveram. Na Alemanha, o Professor Eberhart Zeitler criou experiência com a técnica e continuou a aperfeiçoá-la, enquanto passo a passo outros e o próprio Dotter já vinham pensando em balão para comprimir o ateroma. Notese que cateter com balão inflável na ponta não era uma ideia nova. Já haviam sido concebidos antes, mas não usados para dilatar artérias periféricas: havia um para ocluir um ramo homolateral da artéria pulmonar em testes pré-pneumectomia e verificar se o fluxo desviado para o outro lado não produzia hipertensão pulmonar que contraindicasse a cirurgia, e também o cateter de Fogarty para remoção de trombo, sem falar nos balões para dilatação uretral e esofagiana. Na década de 1970, Richard Myler tentara desenvolver um para coronárias e Dotter chegou a usar outro em 1974 para dilatação periférica, sem receber atenção. Foi quando surgiu uma figura carismática.

Primeiro e fundamental avanço, o balão de Gruentzig: Andreas Gruentzig ${ }^{108}$ era um jovem médico alemão treinado em epidemiologia e saúde pública e depois em medicina interna, mas queria mais. Após estágio em radiologia vascular com o Professor Zeitler na Alemanha, em 1970, retornou à Suíça e usou a técnica para dilatar artérias periféricas e renais, e em 1972 começou a conceber um balão de látex adicionado ao cateter de Dotter. Por sugestão de Hopff, um engenheiro de plásticos, desenvolveu um balão de polyvinyl-chloride (PVC), inflável, mas pouco complacente, trabalhando à noite e em fins de semana, geralmente na sua cozinha. Em 1973 e 1974, já fellow em cardiologia, fez experiências em animais e em artérias periféricas de pessoas, colocando por meio de cateter seu balão dentro de uma artéria sobre a placa aterosclerótica, insuflando-o, esmagando a placa e refazendo a circulação do sangue sem resistência. Esse foi o tema de sua habilitação para obter o título de Privatdozen (uma espécie de livre-docente) da Universidade de Zurique, 
na Suíça. Criou-se, assim, a angioplastia transluminal percutânea, capaz de comprimir as lesões obstrutivas arteriais contra a parede e refazer a luz do vaso, incluindo artérias periféricas, renais, ileofemorais e poplíteas. Depois de miniaturizar o balão para experiências em artérias coronárias de cães, em 1974, apresentou com Hopff o protótipo dos cateteres atuais de angioplastia coronariana. No ano seguinte, construiu o balão de dupla luz que, em 1976, passou a ser fabricado pela Schneider and Cook Co.

Depois de algumas fibrilações nos primeiros cachorros testados, o que levou à perfusão das artérias coronárias durante os procedimentos, Gruentzig ${ }^{109,110}$ continuou com vários experimentos em cães e em cadáveres, em 1976, culminando com a dilatação de artérias coronárias em humanos por meio da insuflação do já citado balão de PVC, com diâmetro aproximado ao da artéria, durante cirurgias de revascularização miocárdica, em cooperação com Myler, Hanna e Turina ${ }^{111}$, em São Francisco, nos Estados Unidos. Colocavam retrogradamente, via arteriotomia coronariana, antes do implante da ponte de safena, um balão de dilatação sobre a lesão proximal e dilatavam a artéria. Temerosos de possíveis tromboses ou embolizações por fragmentos do ateroma, depois de remover o cateter lavavam a artéria coronária através de uma cânula e filtravam o efluente, sem encontrar nenhum fragmento. Exames posteriores demonstraram a permanência da dilatação e confirmaram ausência de sequelas, mas o método não despertou grande entusiasmo entre os cardiologistas.

Depois de muitos testes durante coronariografias diagnósticas em Zurique e São Francisco, medindo-se gradientes intracoronarianos translesões e treinando angiografia superseletiva, finalmente, em 16 de setembro de 1977, em Zurique, diante do chefe da cardiologia, um cirurgião, anestesiologista, numerosos cardiologistas e radiologistas, Gruentzig ${ }^{112}$, usando seu novo balão miniaturizado, dilatou exitosamente (normalização da pressão coronariana distal registrada através do segundo lúmen do balão e desaparecimento da estenose à angiografia), com duas insuflações, a artéria coronária descendente anterior de um homem de 38 anos, com angina de recente começo por estenose circular grave de paredes lisas, única e proximal nessa artéria. Efetivou, assim, a primeira angioplastia coronariana transluminal percutânea (ACTP) em humano no mundo. A segunda foi realizada por Kaltenbach e Kober, introduzindo dessa maneira a ACTP na Alemanha113. Referindo-se ao primeiro caso, Gruentzig julgou sua realização mais fácil do que pensava, chegando a dispensar a perfusão distal que havia planejado para a artéria. Um mês depois o paciente foi coronariografado e o bom resultado se mantinha. Esse paciente foi novamente examinado 5 e 10 anos depois. Nesta última vez foi examinado na Emory, para onde o levaram especialmente. Quando verificada a manutenção da patência da artéria coronária, a audiência irrompeu em comovedor aplauso à memória de Gruentzig.

Parece que o entusiasmo do primeiro doente com o resultado superou o de Gruentzig. Apesar do sigilo mantido por Gruentzig, o paciente, do leito do hospital, avisou um repórter sobre o espetacular sucesso e Gruentzig teve que usar toda sua habilidade de convencimento, que não era pouca, para que a notícia não fosse veiculada na imprensa leiga até ser publicada, em 1978, a carta ao editor que enviaria para o Lancet $^{112}$. Mais quatro angioplastias coronarianas realizou Gruentzig em 1977, sem nenhuma complicação. Note-se que duas delas abordaram estenose em tronco da artéria coronária esquerda, curiosamente na época considerados casos ideais. Só depois as potenciais complicações de casos semelhantes começaram a assustar, ouvi do próprio Gruentzig. Apresentação desses casos no meeting da American Heart Association em 1977, em Miami, desta vez despertou entusiasmo.

Em março de 1978, Richard Myler, que acompanhou Grüntzig desde os primeiros casos, e Simon Stertzer introduziram no mesmo dia, um pela perna, em São Francisco, e outro pelo braço, em Nova York, a ACTP nos Estados Unidos ${ }^{113}$. Nesse mesmo ano, Gruentzig publicou a famosa carta ao editor no Lancet $^{112}$, mostrando a técnica e os resultados dos primeiros cinco casos. Em 1979, divulgou seus primeiros 50 casos no New England Journal of Medicine ${ }^{114}$, em que predominavam bons resultados. Habitualmente os pacientes eram mantidos com 500 mg a 1.500 mg de aspirina diários, muito mais que hoje. Estava inaugurada a aplicação rotineira da ACTP, método que revolucionou o tratamento de pacientes com cardiopatia isquêmica e que nestes últimos 30 anos vem oferecendo crescentes perspectivas terapêuticas, beneficiando milhões e milhões de pessoas no mundo ${ }^{115}$.

O grande toque genial de Gruentzig ${ }^{114}$ foi a concepção do cateter-balão inflável de dupla luz, com pequeno segmento de guia fixa na ponta, para não lacerar a artéria coronária. A insuflação permitia enchimento a um diâmetro pré-determinado com 2 atm a 10 atm ou mais, cujo diâmetro apropriado e material resistente (PVC e depois polietileno) impediam superdistender a artéria coronária. Assim era possível ao balão atingir diâmetro de $9 \mathrm{~F}$ a $12 \mathrm{~F}(3 \mathrm{~mm}$ ou $4 \mathrm{~mm}$ ) dentro da artéria coronária, porém levado por um cateter de $6 \mathrm{~F}$. Um lúmen servia para inflar e desinflar o balão e outro para medir pressões intracoronarianas pré e pós-dilatação e injetar contraste. Esse balão reinou soberano por muitos anos. Entretanto, a combinação de rigidez, ausência de guia condutora, o que dificultava sua colocação sobre lesões mais distais, diâmetro de $1,5 \mathrm{~mm}$ do balão desinflado, e baixa pressão de ruptura de 6 atm fez esse dispositivo elegível para não mais que $5 \%$ dos pacientes com coronariopatia requerendo cirurgia, ou seja, para aqueles com estenoses proximais, concêntricas, não calcificadas, longe de 
bifurcações e únicas. Hoje o quadro mudou, e cerca de $95 \%$ dos casos que poderiam ser cirúrgicos podem ser tratados por angioplastia ${ }^{115}$.

Em 1977 iniciou-se o primeiro registro de ACTP pelo National Heart Lung and Blood Institute. O percentual de sucesso nos casos entre 1977-1981 era em torno de $65 \%$ nas lesões abordadas e a incidência de cirurgia de revascularização de urgência era de cerca de $6 \%{ }^{116}$, números modestíssimos em relação aos atuais. Não obstante, a progressiva aceitação da ACTP referendou o conceito de desobstrução vascular lançado inicialmente por Dotter. Fundamental impulso centrouse em cursos de demonstração ao vivo iniciados por Gruentzig em 1978, em Zurique, para onde acorriam interessados de todo o mundo, a fim de se credenciar para realizar o procedimento. A ACTP nos anos iniciais precisou ser apoiada pela cirurgia de plantão e não era raro mandar o paciente para revascularização cirúrgica do miocárdio logo após um procedimento inefetivo ou complicado. No início, os maiores problemas da angioplastia eram atingir lesões mais distais - por ausência de guia dirigível -, cruzar a estenose ou oclusão, dilatar lesão rígida ou calcificada, desenvolver oclusão aguda e aparecer, entre dois e seis meses depois, reestenose do vaso.

Os primeiros cateteres-guia primavam pela rusticidade, tinham $9 \mathrm{~F}$ a $10 \mathrm{~F}$ e revestimento de teflon, com pobres memória e torque. Uma das grandes dificuldades da época consistia em canular a artéria da lesãoalvo. Em 1980, realizaram-se pouco mais de mil ACTPs nos Estados Unidos, mas começaram a se desenvolver novos modelos de cateteres-guia para femoral e, em 1982, Stertzer introduziu o cateter-guia para abordagem das artérias coronárias via artéria braquial ${ }^{113}$, que continuaram utilizando novos materiais (PET) com camadas de teflon, seda e poliuretano, com menores perfis, pontas mais moles e uma variedade de formas e curvas para melhor cateterizar o vaso-alvo, que evoluíram em direção a menores diâmetro e espessura parietal e maiores torque, memória e resistência a pressões superiores a $20 \mathrm{~atm}$, chegando às guias de $6 \mathrm{~F}$ que hoje permitem não só passar o cateter-balão como implantar stents. Por essa época também deixou-se de considerar a ACTP um suave método de remodelamento da artéria coronária e passou-se a reconhecê-la como uma agressão endotelial traumática pelo instrumento de dilatação percutânea, que rompe e quebra a placa e provoca dissecção da camada íntima do vaso, iniciando um processo de reação cicatricial por proliferação de células musculares lisas e levando a hiperplasia intimal, que pode terminar em reestenose, e mesmo reobstruir o vaso previamente tratado $^{117}$. Depois se aprendeu que, mais que tudo, a reestenose liga-se a características da lesão e ao resultado do procedimento, seja realizado só com balão ${ }^{118}$ ou com balão mais stent ${ }^{119}$.

Embora não decorrente de investigação sistemática, cabe aqui registrar que a primeira desobstrução de artéria coronária por cateterismo documentada no mundo foi realizada em São Paulo, Brasil, por Galiano et al. ${ }^{120}$, ao perfurar um trombo oclusivo de artéria coronária direita com cateter de Sones, recanalizando a artéria e produzindo imediata melhora no paciente, que se encontrava em choque. Estando eu presente na sessão de temas livres no Congresso Brasileiro de Cardiologia, em Brasília, em 1971, quando Galiano apresentou esse caso, ainda recordo o ar de estupefação da plateia não acreditando no que via e não percebendo bem que estava presenciando a primeira angioplastia coronariana realizada no mundo!

Pelo método de Gruentzig, a ACTP foi realizada pela primeira vez no Brasil, em 1979, em Curitiba, por Costantino Costantini ${ }^{121}$ e, logo a seguir, por J. Eduardo Sousa ${ }^{122}$, em São Paulo. Em 1980, organizei o V Congresso Brasileiro de Hemodinâmica e Angiocardiografia ${ }^{123}$, em Canela, RS, tendo como convidado oficial o Professor Richard Myler, em sua primeira vinda ao Brasil. Naquela época, os cateteres-balão eram tipo G e DG, abandonados há muito, rígidos e sem guia dirigível. Myler apresentou sua fantástica e fascinante experiência de 150 casos, obtendo ótimo sucesso primário em torno de $60 \%$ nos casos de indicação clássica! Tive o privilégio de trabalhar com ele em São Francisco, em 1981. Myler é um sujeito maravilhoso, amigo, nunca escondeu o que sabe, procurou sempre divulgar a técnica em todos os cantos do mundo. Tivemos a honra de recebê-lo por duas vezes em Porto Alegre.

Pouco depois desse estágio com Myler, em São Francisco, em 1982 iniciávamos a angioplastia coronariana no Instituto de Cardiologia do Rio Grande do Sul e no Estado. Naquele tempo, o percentual de sucesso era em torno de $60 \%$, isso em lesões simples e proximais, as únicas elegíveis para angioplastia. Como os casos eram muito selecionados, apesar do primitivismo dos recursos, a mortalidade ficava em torno de $1 \%$, número que permaneceu ao longo dos anos até a era do stent. Nosso primeiro caso ${ }^{124}$ - do qual participaram o inesquecível Siguemituzo Arié, vindo de São Paulo para nos auxiliar, e o dr. Vasco Miler - foi marcante: tratava-se de um homem com 35 anos de idade, apresentando quadro típico de angina de recente começo por lesão proximal tipo A na artéria descendente anterior, cujo diagnóstico fora feito em maio e a dilatação efetivada em agosto, porque, por ser o primeiro caso, exigia muita preparação.

Aconteceu que quando fomos dilatar a artéria coronária, eu, Vasco e Arié (então com a vastíssima experiência de 40 casos por balão), a artéria coronária havia fechado sem infarto, devido à ampla circulação colateral a partir da artéria coronária direita. Sem saber o que fazer, pois na época não havia divulgação de angioplastia nesses casos, perguntei para ambos (eles tambem não sabiam): e agora? Arié me respondeu: Está na coronária, empurra o cateter. E assim, na ponta 
do cateter de Gruentzig, tipo G, há muito abandonado, depois de injetar-se contraste surgiu uma longa e radiosa artéria descendente anterior! É esse o primeiro caso documentado ${ }^{124}$ de desobstrução de artéria coronária cronicamente ocluída em nosso País. Depois, revisando a literatura, vi que, por pouco, não foi o primeiro no mundo, pois Savage et al. ${ }^{125}$ haviam feito o mesmo meses antes! O melhor de tudo é que esse paciente, estudado 10 anos depois, estava com a artéria coronária perfeita e assintomático. Até hoje se mantém ativo e livre de sintomas, agora com 62 anos. $\mathrm{O}$ balão, o primeiro grande e fundamental avanço para se realizar ACTP, permitia essas coisas, mas não atingia vasos muito distantes.

Cidadão do mundo, Gruentzig realizou seu trabaIho pioneiro na Universidade de Zurique, onde, em 1979, tornou-se chefe do Departamento de Cardiologia do hospital universitário, depois se mudou para os Estados Unidos, desenvolvendo sua atividade na Universidade Emory. Ganhando a peso de ouro, atingiu o ápice da fama, comprou um avião e vitimou-se do prazer malsucedido de pilotar, quando faleceu com a segunda esposa numa queda em Atlanta, nos Estados Unidos, em 1985. Dotter, Sones e Judkins também morreram nesse ano. Ano trágico para a cardiologia intervencionista. Não pode ser esquecido que, antes de morrer, a mente inquieta de Gruentzig já cogitava de vários dispositivos que surgiram depois, como laser, stents, aterectomia, êmbolos de colágeno, ultrassom, e valvas cardíacas por via percutânea.

Importante auxílio desde essa época até a atual têm representado os registros evolutivos e estudos randomizados comparativos de pacientes submetidos a ACTP, desenhados para investigar os benefícios relativos de angioplastia de múltiplos vasos comparados com cirurgia de revascularização miocárdica, de ACTP primária no infarto comparada com trombolítico, de stents convencionais comparados com eluídos, enfim de todos os tipos de acompanhamento e testagem que possam ser feitos para melhor responder à pergunta de como selecionar o método preferencial ou a meIhor técnica, se intervencionista ou cirúrgica, nos diversos campos da Cardiologia, muitas já com respostas a favor da intervenção por cateter ${ }^{115}$.

Segundo grande avanço, o guia de Simpson: Pouco ressaltada na técnica de angioplastia coronariana é a guia de Simpson et al. ${ }^{126}$. John Simpson fez essa extraordinária contribuição no começo de sua carreira acadêmica em Stanford, nos Estados Unidos, no início da década de 1980. Conhecedor do cateter over-the-wire usado pelos radiologistas na angiografia vascular desde a década de 1960, percebeu que o melhor uso do segundo lúmen do cateter de Gruentzig não seria para medir pressões ou injetar contraste, mas para dar passagem a uma guia 0,014 polegada, independente, maleável e moldável, capaz de atingir locais mais distantes e angulações da árvore coronariana, entrar em bifurca- ções, colocar dois guias para passar dois balões sobre lesões diferentes para, sobre ele, lá chegar com o cateter-balão. Com a introdução da guia de Simpson foram possíveis maiores opções de dilatação e a obtenção de mais sucesso, enorme avanço. Contou-me Myler que o entusiasmo do jovem com sua invenção foi tão grande que a energia liberada ao demonstrá-la para o veterano Dotter rompeu o balão e encheu de contraste os óculos e o impecável terno do velho mestre, que vibrou com a novidade!

O aperfeiçoamento da concepção de Simpson levou a guias e balões com menos de $0,5 \mathrm{~mm}$ desinflados e capazes de resistir a pressões superiores a 20 atm, permitindo aumentar os índices de sucesso da ACTP para $85 \%$ das lesões abordadas, nos registros de 1985$1986^{127}$. Esses fatos estimularam Hartzler et al. ${ }^{128}$, em Kansas City, nos Estados Unidos, a estender a nova técnica para infarto agudo do miocárdio e múltiplos vasos num mesmo procedimento. A ACTP tornava-se multipotente. Assim é que 10 anos depois de seu início faziam-se mais de 250 mil ACTPs por ano só nos Estados Unidos, sem falar de outros recordes em todo o mundo, atingindo mais ou menos a metade das revascularizações cardíacas. Mais 10 anos e esse número dobraria, devido à multiplicação de centros de cardiologia intervencionista em todo o mundo, o que ainda continua ocorrendo.

No tempo do balão definia-se sucesso inicial geralmente como estenose residual $<50 \%$ do lúmen do vaso e fluxo TIMI 3, sem eventos cardiovasculares maiores (óbito, infarto, revascularização cirúrgica ou reintervenção no vaso-alvo). Reestenose tardia definiase como reaparecimento de estenose maior que 50\% do lúmen no local previamente dilatado com sucesso. Além da medicação vasodilatadora habitual, antes do procedimento administravam-se 5 a 10 mil unidades de heparina e logo após usava-se dipiridamol para evitar espasmo da artéria coronária, sendo os pacientes mantidos por pelo menos um ano com $100 \mathrm{mg}$ a $500 \mathrm{mg}$ de aspirina por dia. Entretanto, a ACTP continuava a oferecer entraves insuperáveis em muitos casos, como dificuldade de cruzar lesões oclusivas, dilatar lesões muito calcificadas ou muito elásticas, prevenir reoclusão aguda por dissecção, espasmo ou trombose, e surgir reestenose depois de meses, em decorrência de hiperplasia tecidual no local dilatado ${ }^{129}$.

Diferentes pesquisadores tentavam resolver esses problemas quando novamente Simpson et al. ${ }^{130}$ criaram a aterectomia direcional, o primeiro dispositivo sem balão para ACTP, que, ao invés de esmagar e romper, corta o ateroma. Depois surgiram a aterectomia rotacional $^{131}$ e extrativa, laser para abrir caminho vaporizando a placa obstrutiva (mais indicada para lesões longas, oclusões totais, lesões ostiais e placas calcificadas), remoção, lixamento e extração por vácuo, todos métodos que, depois de um período de euforia, logo se mostraram decepcionantes ${ }^{115,132,133}$ pelo núme- 
ro de complicações provocadas (dissecções, tromboses, embolias), sem falar no laser, que, além de inefetivo, desperdiçou fortunas. A aterectomia rotacional usa diferentes pontas ovaladas revestidas de fragmentos microscópicos de diamante que giram a até 200.000 rpm e "desbastam" ou lixam o ateroma. Também não se mostrou superior à ACTP por balão ${ }^{133}$. Esses métodos, que nunca nos seduziram, mesmo quando na moda e bem remunerados, acabariam sepultados pelos stents. Atualmente, raramente a aterectomia rotacional é usada em lesões calcificadas ostiais ou em bifurcações, antes do implante de stents.

Terceiro avanço, progressos correlatos: Em toda sua história, a ACTP valeu-se paralelamente de avanços fisiológicos, anatomopatológicos, farmacológicos, clínicos, e instrumentais. É impossível esquecer esse terceiro avanço, que na verdade a acompanha desde seus primórdios, ou seja, o melhor conhecimento da história natural da aterosclerose, o adequado reconhecimentos das lesões, as indicações mais precisas e os coadjuvantes terapêuticos mais eficazes. Ambrose et al. ${ }^{134}$ publicaram, em 1985, uma classificação morfológica das lesões coronarianas, correlacionandoas com o quadro clínico, e o American College of Cardiology e a American Heart Association também, em $1988^{135}$. Depois houve a introdução do ultrassom intracoronariano e do pressure wire, progresso no tratamento medicamentoso para prevenção da agregação plaquetária e consequente trombose, ressaltandose a eterna aspirina, anticoagulantes, trombolíticos, antitrombóticos, inibidores da glicoproteína IIb/IIla, tienopiridinas, ticlopidina e clopidogrel. Avanço paralelo ao cateterismo arterial tem sido o controle do sangramento pós-procedimento, pela combinação do uso de cateteres menos calibrosos (de $9 \mathrm{~F}$ para $6 \mathrm{~F}$ ), maior experiência com a compressão arterial, compressores mecânicos e colágeno hemostático surgido por 1993, que, colocado sobre o sítio da punção, permite imediata remoção da bainha após retirar o cateter, mesmo em pacientes heparinizados.

Os critérios anatômicos como orientação para ACTP por balão foram referendados em 1988 por força-tarefa americana ${ }^{135}$ - American College of Cardiology e American Heart Association - e agrupados em três tipos: tipo A, lesão de baixa complexidade (proximal, concêntrica, < $10 \mathrm{~mm}$, paredes lisas, não calcificada, longe de bifurcação ou óstio, sem trombo), índice de sucesso primário $>85 \%$ e de complicações $<3 \%$; tipo B, lesão de moderada complexidade $(10 \mathrm{~mm}$ a $20 \mathrm{~mm}$, excêntrica, moderada tortuosidade, ângulo $>45^{\circ}$ $<90^{\circ}$, contorno irregular, moderada calcificação, oclusão > 3 meses, ostial, em bifurcação, algum trombo), índice de sucesso primário de $60 \%$ a $85 \%$ com $3 \%$ a $7 \%$ de complicações; e tipo C, lesões de grande complexidade (> $20 \mathrm{~mm}$, excessiva tortuosidade, ângulo $>90^{\circ}$, oclusão $>3$ meses com saída de colaterais, impossível proteger ramos, ponte de safena degenera- da) que podem ter contraindicação para ACTP, principalmente se suprirem grande área de miocárdio viável (sucesso < 60\% com complicações > 7\%). Com a evolução do material e da técnica de ACTP, esses índices de sucesso e de complicações melhoraram, tanto que na última revisão a força-tarefa da American Heart Association e do American College of Cardiology, em $1993^{136}$, não colocou mais percentuais de sucesso ou insucesso. Em 1990, Ellis et al. ${ }^{137}$ sugeriram que as lesões tipo B fossem divididas em B1 (uma característica desfavorável) ou B2 (duas ou mais características desfavoráveis), o que se mostrou útil em antever mais dificuldade e menos sucesso.

Essa classificação nunca foi isenta de críticas, pois não delimita bem algumas fronteiras, mistura critérios de apenas dificuldade no procedimento (por exemplo, oclusão crônica) com outros que podem indicar complicações graves (por exemplo, trombo intraluminal), além de que nem todas as decisões do intervencionista podem ser orientadas por ela. Perdeu quase toda a força depois do advento dos stents, trombolíticos, filtros, antitrombóticos e novos dispositivos. Entretanto, seu conhecimento histórico ilustra como a cardiologia intervencionista tem conseguido vencer barreiras. Com o auxílio do armamentário atual para ACTP, e a nossa experência confirma, o sucesso primário em lesões tipo A e B1 supera 99\%; no tipo B2, ultrapassa 98\%; e no tipo C, é superior a $90 \%$.

O primeiro cateter usado por Grüntzig já permitia medir rotineiramente o gradiente pressórico intracoronariano translesão. Considerava-se ótimo resultado um gradiente transestenose residual menor que $20 \mathrm{~mm}$. Entretanto, essa possibilidade tornava os balões mais rígidos e a informação geralmente concordava com a imagem. Simpson trocou-a com enorme vantagem pela guia dirigível passando através do conduto que servia para medir pressão, o que resultou excelente para diminuir o perfil dos balões e principalmente expandir as probabilidades de atingir lesões difíceis. Entretanto, em muitos casos a angiografia, que fornece evidências anatômicas e avaliação visual do fluxo intracoronariano, não permite inferir precisamente sobre as condições deste. Para sanar tais dificuldades surgiram vários dispositivos com o fim de quantificar a repercussão fisiológica da estenose intravascular, principalmente o pressure wire e o ultrassom.

Um dos métodos mais simples é a medida antes e depois da angioplastia coronariana, por balão ou stent, do gradiente transestenose pelo pressure wire ${ }^{138}$. Esse cateter possui um orifício proximal e outro distal. Colocando o cateter sobre a lesão, o orifício proximal transmite a pressão aórtica e o distal, a pressão pósestenose. Numa obstrução importante, a pressão distal cai em relação à proximal, antes da lesão. Quanto mais a relação entre a pressão distal e a pressão proximal for progressivamente menor que 0,8 , há indicação de crescente isquemia significativa e necessidade de an- 
gioplastia, enquanto numa relação entre pressão distal e pressão proximal superior a 0,8 não há sugestão de sofrimento isquêmico por redução significativa de fluxo ${ }^{138}$.

A introdução do ultrassom intravascular (IVUS) para exame das artérias coronárias ${ }^{139}$, em 1989, permitiu visualizar o interior do vaso e é fundamental para demonstrar a normalidade estrutural da artéria ou as características anatomopatológicas da lesão aterosclerótica coronariana, ensinar um pouco mais sobre a placa, placa mole, placa dura, presença de trombo ou não e colocar cautela nas decisões. Foi demonstrado: que área luminal mínima da artéria coronária $\geq 4 \mathrm{~mm}^{2}$ tem alta acurácia para prever reserva de fluxo coronariano igual ou maior que $2^{140}$; que paciente com área luminal mínima da artéria coronária $\geq 4 \mathrm{~mm}^{2}$ ao IVUS seguido por mais de ano apresenta muito baixa probabilidade de evento cardíaco ${ }^{141}$; que o diâmetro da lesão coronariana pelo IVUS é o mais importante preditor quantitativo de eventos cardíacos e que para qualquer diâmetro luminal mínimo os eventos aumentam em presença de diabete e de lesão > 50\% não tratada ${ }^{142}$.

Apesar de domadas grandes dificuldades nesses campos, pelos avanços citados continuavam a se manifestar, embora em menor proporção, espasmos, recolhimento elástico, oclusões agudas e tromboses pósACTP, principalmente em casos de lesões mais complexas. Surgiram cateteres para perfusão mais prolongada, o mais usado sendo o cateter de Stack ${ }^{143}$, enquanto a placa instável "colava", mas muitas vezes o mau resultado não revertia. Em 1986 chegaram a ser usados alguns dispositivos de retroperfusão pelo seio coronariano, com a antifisiológica e hipotética finalidade de oxigenar o miocárdio, porém com alguns resultados favoráveis ${ }^{144}$.

Quarto grande avanço, os stents: Outro fundamental e revolucionário avanço, que mudou a face da angioplastia, foi o stent, cuja concepção já é bem antiga. Experiências de Aléxis Carrel ${ }^{145}$ em cachorros, em 1912, fizeram surgir a ideia de "intubações permanentes" em vasos traumatizados, tratando-os com próteses vítreas em forma de tubo. Muito depois, Dotter $^{146,147}$ implantou tubos plásticos e metálicos, trabalhando também com nitinol (um alógeno de níquel e titânio que se expande a um tamanho predeterminado), em artérias de cachorros porque seu método de dilatações sucessivas produzia muitas tromboses. Assim, já na década de 1970 Dotter $^{146}$ avançara o conceito de próteses metálicas endoluminais para manter as artérias coronárias abertas. A ideia básica por trás disso é proteger a parede arterial de cortes, traumas e rupturas produzidas por intubações sucessivas ou aterótomos.

Embora o termo "stent" já fosse usado na Inglaterra desde o século XIV como designativo de um instrumento para espalhar redes de pesca nos rios, no que tange à angioplastia considera-se que proveio do nome do dentista Charles Stent, inventor de materiais médicos no século XIX, entre os quais uma substância plástica usada na $1^{\underline{a}}$ Guerra Mundial para estabilizar transplantes de pele, chamados de "stents moldes". Depois o termo stent passou a ser usado nas áreas de cirurgia oral e plástica e a seguir expandiu-se para outros tipos de suportes artificiais para tecido humano, em sequência, para suporte tubular na cirurgia cardiovascular, em 1966, e em cardiologia intervencionista a partir de 1987.

As preparações iniciais dos modernos stents expansíveis começaram com Cragg et al. ${ }^{148}$, em 1982, e Palmaz et al. ${ }^{149}$ pouco depois. Entretanto, não foram usadas em pacientes até 1984, quando Sigwart et al. ${ }^{150}$, na Suíça, utilizaram uma estrutura tubular autoexpansiva, feita de fina rede de aço inoxidável, em artérias periféricas e depois nas artérias coronárias, que foi chamada wallstent, visando diminuir os inaceitáveis índices de reestenose pós-balão. Para implantar esse primitivo stent desenvolveram um sistema capaz de remover sem fricção a membrana constritora envolvente; depois, o stent podia ser dilatado por balão. O tratamento farmacológico constava de $1 \mathrm{~g}$ de aspirina no dia anterior e após, 15.000 unidades de heparina intravenosa imediatamente antes do procedimento, e 50.000 a 100.000 unidades de uroquinase durante o procedimento, infundidas lentamente na artéria coronária pelo cateter-guia. Heparina intravenosa continuava no pósoperatório até que a anticoagulação oral com cumarínicos se tornasse efetiva. Todos os pacientes recebiam bloqueadores de canais de cálcio, $330 \mathrm{mg}$ de aspirina e $75 \mathrm{mg}$ de dipiridamol por dia, iniciando quatro a oito horas após o procedimento. Mesmo assim, frequentemente ocorriam tromboses dos stents.

Nada parecido com os stents flexíveis de múltiplos elos e grande força radial já montados e expansíveis por balão usados atualmente, administrando-se $300 \mathrm{mg}$ a $450 \mathrm{mg}$ de clopidogrel e $200 \mathrm{mg}$ de aspirina antes, 10.000 unidades de heparina imediatamente antes, mantendo-se depois os pacientes simplesmente com $100 \mathrm{mg}$ a $200 \mathrm{mg}$ de aspirina indefinidamente e $75 \mathrm{mg}$ de clopidogrel ou $300 \mathrm{mg}$ de ticlopidina por tempo determinado, e baixíssima incidência de tromboses.

Em 1984, Palmaz colocou stents expansíveis montados sobre balão em múltiplas artérias, tendo sido o primeiro a publicar trabalho experimental nessa área ${ }^{149}$. Junto com Schatz e outros, espraiou a experiência para uso generalizado na cardiologia clínica. Seu stent de dois elos de $7 \mathrm{~mm}$ articulados por uma junção de $1 \mathrm{~mm}$ possuía razoável mobilidade, permitia a abordagem de curvas e era de mais fácil liberação. Tornou-se por muitos anos, principalmente entre 1994 e 1998, a quase única opção, porém tinha diâmetro de $1,6 \mathrm{~mm}$ desinsuflado, ainda vinha dentro de uma membrana envolvente que necessitava ser retirada depois de colocado sobre a placa, antes de expandi-lo pelo 
balão acoplado. Em 1987, Sigwart apresentou seus resultados no New England Journal of Medicine, mostrando claramente o valor dos stents em prevenir recoil agudo e reestenose tardia ${ }^{150}$.

Tudo evolui passo a passo. Apesar das indicações iniciais limitadas a dissecção aguda, recolhimento elástico e oclusão aguda - e depois indicações eletivas para otimização de resultados, lesões selecionados, e incipientemente à prevenção da reestenose -, as primeiras séries de stents implantados esbarravam nas assustadoras tromboses em torno de $20 \%$ dos $\operatorname{casos}^{151}$, a despeito do uso combinado de aspirina, dipiridamol, dextran e heparina. Muitos pacientes morriam, infartavam ou iam para cirurgia de urgência. O mesmo aconteceu com o primeiro stent expansível por balão de Julio Palmaz e Richard Schatz. No entanto, a providencial combinação de aspirina e passagem da heparinização venosa para anticoagulação oral (cumarínico) reduziu tais eventos para 3\%, embora aumentasse o período de hospitalização para uma semana e as hemorragias para $10 \%{ }^{151}$.

Provavelmente o primeiro implante de stent em situação aguda foi feito por Sigwart, quando, após uma demonstração de ACTP, o paciente desenvolveu sinais de fechamento da artéria coronária descendente anterior, logo confirmado pela coronariografia. Ainda hesitante, Sigwart colocou um stent de urgência, seguido por imediato entusiasmo da plateia e melhora do paciente, que permaneceu assintomático ${ }^{7}$. Em 1993 foi introduzido o stent de Gianturco-Roubin ${ }^{152}$ para reversão de oclusão aguda pós-angioplastia por balão. Gianturco inventou o protótipo do primeiro cateterbalão para intervenção vascular, em 1951, o filtro para veia cava, em 1985, e um stent para abrir veia cava estenótica $^{9}$. O primeiro implante de stent coronariano no Brasil ocorreu em 1987, no Instituto Dante Pazzanese de Cardiologia, realizado por Sousa et al. ${ }^{153}$.

Dois ensaios clínicos randomizados, Stent Restenosis Study (STRESS) ${ }^{151}$ e BElgian NEtherlands STENT study (BENESTENT) ${ }^{154}$, publicados no New England Journal of Medicine, foram decisivos para incentivar a utilização dos stents em artérias nativas e pontes de safena a partir de 1994. Tanto STRESS (410 casos) como BENESTENT (520 casos) evidenciaram a superioridade do implante primário de stent sobre a angioplastia por balão quanto a sucesso inicial, maior ganho luminal inicial e menos reestenose tardia, que caiu pela metade. Combinando os eventos cardiovasculares maiores (reaparecimento da angina, revascularização do vaso-alvo devido a reestenose, infarto e morte), depois de três meses havia uma grande separação das duas curvas, principalmente pela diminuição da reestenose. Esses trabalhos consagraram o stent como escolha na angioplastia. Ambos ${ }^{151,154}$, porém, notaram excesso de sangramentos no sítio da punção, devido ao exagero de anticoagulação e calibre das bainhas. Aprovados oficialmente os stents para uso em 1994, já em 1997 dividiam a metade das revascularizações coronarianas com a cirurgia. Multiplicaram-se os tipos de stents, quanto a perfis, tamanhos e calibres.

Marie Claude Morice ${ }^{155}$, na França, e Antonio Colombo ${ }^{156}$, na Itália, trouxeram a contribuição de demonstrar que a técnica de liberação ótima do stent - com alta pressão, aspecto stent like verificado pelo IVUS ou perfeitamente pela angiografia -, diminui a trombose subaguda para menos de $1 \%$, apesar da eliminação do anticoagulante oral, administrando-se apenas aspirina e ticlopidina. O esquema pós-stent de aspirina $200 \mathrm{mg} / \mathrm{dia}$, indeterminadamente, e ticlopidina $500 \mathrm{mg} / \mathrm{dia}$, no primeiro mês, originou melhores resultados na prevenção da trombose subaguda que o uso isolado de aspirina ou de aspirina mais cumarínico $^{157}$. A alta pressão de implantação do stent, combinada com aspecto angiográfico ótimo pós-procedimento, passou a dispensar o uso de IVUS. Essa conduta tornou o implante de stent mais fácil e fez proliferar modelos e aperfeiçoamentos em gerações de novos stents, que começaram também a servir como plataformas para liberação de drogas locais, genes ou radiação, tudo com a finalidade de controlar a reestenose que continuava em torno de $20 \%$ dos casos. Nada disso deu resultado significante.

O estudo STent versus directional coronary Atherectomy Randomized Trial (START) ${ }^{158}$, publicado em 1999, mostrou resultados a longo prazo francamente favoráveis ao stent quanto ao declínio do aparecimento de eventos cardiovasculares. Quando chegou em 420 casos, foi interrompido para não prejudicar o braço dos pacientes que caíam na angioplastia convencional. Nessa altura da história da ACTP ressaltam como maiores eventos históricos: o conceito de Dotter de recanalização de artérias ateroscleróticas por cateter, a técnica de Seldinger de cateterização percutânea retrógrada, o balão de Gruentzig para dilatação coronariana por via percutânea, a guia de Simpson e o stent. Essas conquistas é que realmente formam a base de todo o avanço técnico do cateterismo cardíaco terapêutico, reinando sobre a inumerável variedade de novos dispositivos ${ }^{9,115}$. O resto é colateral; por vezes protagonizou o efeito principal de fazer lucrar a indústria e engordar alguns honorários.

Nosso grupo de trabalho no Laboratório de Hemodinâmica e Cardiologia Intervencionista do Instituto de Cardiologia do Rio Grande do Sul teve a oportunidade de apresentar e publicar trabalhos ${ }^{119,159}$ baseados na ideia de estratificar a reestenose pós-implante de stents convencionais por meio de um escore que leva em conta o comprimento da estenose, o calibre pós-angioplastia, e a presença ou não de diabete. O escore foi construído dando pesos proporcionais a esses dados, conforme análise multifatorial. Verificou-se que, quando o individuo não é diabético, quando o stent é de até $11 \mathrm{~mm}$ e quando o diâmetro luminal mínimo é de $3,5 \mathrm{~mm}$ ou mais, a reestenose atinge apenas $1 \%$ dos 
pacientes pós-stent convencional. A reestenose aumenta progressivamente até vasos longos, finos e pacientes diabéticos, todos fatores independentes de reestenose. Apesar disso, alguns passam a ideia de que a reestenose é um número fixo. Não é um número fixo, depende dos pacientes, do método, do material e, principalmente, das características das lesões ${ }^{118,119,129,159}$. Em vasos periféricos, a reestenose, mesmo só com balão, é muito mais rara porque esses vasos têm calibre maior.

Quinto grande avanço, stents revestidos: Stents revestidos com agentes antiproliferativos carreados por um polímero preso sobre a plataforma metálica dos stents (sirolimus, paclitaxel ou outros) diminuíram ainda mais a reestenose. Sua ação inibe a hiperplasia neointimal pós-ACTP, bloqueando o ciclo celular por mecanismo citostático (fase inicial) ou citotóxico (fase final). Assim é que em 1999 começou a primeira experiência humana com implante revestido com sirolimus, no Instituto Dante Pazzanese de Cardiologia, comandada por J. Eduardo Sousa ${ }^{160}$. O estudo SirolimusEluting Stents versus Standard Stent in Patients with Stenosis in a Native Coronary Artery (SIRIUS), apresentado em 2002 no EuroPCR Meeting em Paris, por Leon e Moses, mostrando os primeiros 400 casos de sirolimus, evidenciou que, seguindo-se esses casos por nove meses, a reestenose no stent convencional ficava em $16 \%$ e no stent revestido, em $5 \%$, ou seja, três vezes menos, o que dá uma credencial muito significativa ao uso dos stents eluídos. Mesmo nos pacientes de alto risco houve redução relativa de $70 \%$ a $80 \%$ na reestenose clínica em um ano ${ }^{161}$. Entretanto, em estudos comparando stent convencional e stent revestido, com período de seguimento variando de seis meses a um ano, a maioria dos trabalhos mostra diminuição do reaparecimento da angina e da reestenose no grupo dos revestidos, o mesmo não ocorrendo com os desfechos infarto ou mortalidade.

Em outubro de 2006, no Congresso Europeu de Cardiologia e na revista European Heart Journal, surgiu um trabalho ${ }^{162}$ indicando a maior mortalidade nos pacientes submetidos a implante de stents revestidos, uma metanálise com estudo de 8.221 casos retirados de nove artigos. Essa metanálise mostrou que a mortalidade total, principalmente no grupo do sirolimus em relação ao do paclitaxel, não era diferente no primeiro ano, mas a partir do segundo, do terceiro e do quarto anos ela aumentava, sendo a maior mortalidade total decorrente principalmente de causas extracardíacas, sem especificação. A mortalidade maior dos stents revestidos em relação ao convencional foi de $0,6 \%$ ao ano, uma diferença muito pequena. Entretanto, o achado serviu para eliminar o exagero de alguns a preconizar que todos os pacientes deveriam receber stents revestidos. Uma explicação razoável para o aumento das mortes cardíacas parece ser trombose tardia associada aos stents eluídos, pois estes inibem a endotelização, que não se completa nem em três anos, enquanto com stent convencional se completa em seis meses. Daí o perigo da retirada do clopidogrel ou da ticlopidina antes de um ano, o que favorece a trombose intrastent. Não há explicação para possível maior mortalidade não-cardíaca.

A polêmica continua, pois outros trabalhos mostram diminuição da mortalidade com a utilização de stents eluídos ${ }^{163}$. O problema parece estar centrado na trombose induzida por retardo da reendotelização consequente à inibição da proliferação endotelial pela droga $^{164}$ - exigindo, por isso, mais tempo de uso de ticlopidina ou clopidogrel associado a aspirina - e/ou no abandono precoce do tratamento ${ }^{165}$, fatores que favorecem a formação de trombo. Stent convencional continua sendo indicado em casos selecionados.

Representando um esforço concentrado por parte de suas lideranças atuais e históricas, a Sociedade Brasileira de Hemodinâmica e Cardiologia Intervencionista, também órgão departamental da Sociedade Brasileira de Cardiologia, e em conjunto com esta, publicou, em 2008, diretrizes de intervenção coronariana percutânea e métodos adjuntos diagnósticos em cardiologia intervencionista, em que são discutidos os principais pontos da especialidade, indicações e níveis de evidência dos diversos métodos instrumentais e medicamentosos atuais para tratamento de coronariopatias por cateter. ${ }^{166}$

\section{Sinopse}

História sobre o cateterismo cardíaco e seus desdobramentos investigativos, diagnósticos e terapêuticos é marcada por paixão, genialidade, serendipidade e consagração do método científico. Começou com Hales em 1711, colocando tubos nos dois ventrículos de um cavalo, no século XIX passou pelo desafio da fisiologia a Claude Bernard, sofisticou-se com a habilidade de Chauveau e Marey, começou a ser aplicado no coração humano pelo arrojo de Forrsmann em 1929, foi desenvolvido sistemática e cientificamente por Cournand e Richards pelo lado direito da circulação na década de 1940, passou para o lado esquerdo do coração por Zimmerman, Cope, Ross, Seldinger na década de 1950, por um acidente entrou nas coronárias pela mão de Sones em 1958, chegando à coronariografia percutânea em 1967, conduzido por Judkins e Amplatz, à angioplastia devido a uma recanalização periférica acidental por Dotter em 1963, tornou-se terapêutico em 1966 por Rashkind, inaugurou a era da recanalização coronariana pelo balão de ACTP de Gruentzig em 1977, conquista que foi ampliada pela guia de Simpson em 1982, pelo stent de Sigwart em 1984 e pelo stent revestido em 1999, por Sousa.

Todo conhecimento humano é feito em cima de milhares de tentativas que depois se mostram inúteis, de montanhas de dinheiro gasto e de toneladas de papel que acabam no lixo. Na trajetória da ciência só permanece um infinitésimo do que é proposto, que acaba sendo aceito por ser acessível, simples, prático, útil, efetivo. Na senda da cardiologia intervencionista, 
dispositivos, medicamentos e condutas em uso geralmente representam a boa sobra que foi filtrada a partir da experiência. Conforme todo processo histórico, as tentativas de solucionar problemas nesse campo também se baseiam em acerto e erro. Conhecem-se mais os acertos que ficaram e foram capazes de originar progressos sucessivos, mas pouco se sabe do que foi descartado por inútil ou por incapacidade de perceber-se a potencialidade. Talvez nem tudo que fazemos tenha sido resultado da melhor opção. O importante é continuar de olhos abertos para as boas pistas.

Cournand $^{15}$ disse que o cateter foi a chave que abriu a fechadura a esconder os segredos do coração. Nestes últimos 80 anos, pioneiros desbravaram caminhos fisiológicos, diagnósticos e terapêuticos, começando com o ventrículo direito e a circulação pulmonar, seguidos pela aorta e ventrículo esquerdo e pela conquista do diagnóstico coronariano e seus desafios de tratamento, que estão sendo vencidos paulatinamente. Quando tudo isso tiver passado e surgirem outros métodos mais diretos, mais simples e mais curativos, ainda assim essa etapa da medicina cardiológica não será esquecida, por ter sido a mais desafiadora, heroica, gloriosa e didática que se dedicou a desvendar os mistérios do coração.

\section{CONFLITO DE INTERESSES} teresses.

O autor declarou inexistência de conflito de in-

\section{REFERÊNCIAS BIBLIOGRÁFICAS}

1. Gottschall C. Pilares da Medicina. A construção da Medicina por seus pioneiros. Rio de Janeiro: Atheneu; 2009.

2. Gottschall C. O sopro da alma e a bomba da vida: 3000 anos de ideias sobre respiração e circulação. Porto Alegre: AGE e IC/FUC; 2000

3. Bernard C. Leçons sur les effets de la Chaleur e sur la Fièvre. Paris: Bailliere; 1876.

4. Bernard C. Leçons de physiologie operatoire. Paris: Bailliere; 1879

5. Chauveau A, Marey E. Determination graphique des rapports du choc du coeur avec les mouvements des oreillettes et des ventricules: experience faite à l'aide d'un appareil enregistreur (sphygmographe). C R Hebd Acad Sci. 1861; 53:662-5.

6. Chauveau A, Marey E. Appareils et experiences cardiographiques. Mem Acad Imp Med (Paris). 1863;26:268-319.

7. Baim D, Bing R. Cardiac catheterization. In: Bing R, editor. Cardiology. The evolution of the science and the art. New Brunswick: Rutgers University Press; 1999. p. 1-29.

8. Forssmann W. Experiments on myself. Memoirs of a surgeon in Germany. New York: Saint Martins Press; 1974.

9. Mueller RL, Sanborn TA. The history of interventional cardiology: cardiac catheterization, angioplasty, and related interventions. Am Heart J. 1995;129(1):146-72.

10. Forssmann W. Die Sondierung des rechten herzens. Klin Wochenschr. 1929;8:2085-7.

11. Zimmerman A. El cateterismo cardiovascular. Barcelona: Editorial Cientifico-Medica; 1969.
12. Klein O. Zur bestimmung des zirkulatorischen minutenvolumens beim menschen nach den Fickschen prinzip. Munchen Med Wochenschr. 1930;77:1311-2.

13. Cournand A, Ranges $H$. Catheterization of the right auricle in man. Proc Soc Exp Biol Med. 1941;46:462-6.

14. Zimmerman HA, Scott RW, Becker NO. Catheterization of the left side of the heart in man. Circulation. 1950;1(3):357-9.

15. Cournand A. Cardiac catheterization; development of the technique, its contributions to experimental medicine, and its initial applications in man. Acta Med Scand Suppl. 1975; 579:3-32

16. Baldwin E, Moore L, Noble R. The demonstration of ventricular septal defect by means of right heart catheterization. Am Heart J. 1944;32:152-62.

17. McMichael J, Sharpey-Schafer E. The action of intravenous digoxin in man. QJM. 1944;13:123-35.

18. Cournand A, Riley RL, Breed ES, Baldwin ED, Richards DW, Lester MS, et al. Measurement of cardiac output in man using the technique of catheterization of the right auricle or ventricle. J Clin Invest. 1945;24(1):106-16.

19. Bradley SE, Ingelfinger FJ, Bradley GP, Curry JJ. The estimation of hepatic blood flow in man. J Clin Invest. 1945;24(6):890-7.

20. Brannon E, Weens H, Warren J. Atrial septal defect. Study of hemodynamics by the technique of right heart catheterization. Am J Med Sci. 1945;210:480-5.

21. Donald KW. The definition and assessment of respiratory function. II. Br Med J. 1953;1(4808):473-8.

22. Rigatto M. Fisiopatologia da circulação pulmonar. São Paulo: Fundo Editorial Byk; 1973

23. Prates P. Pequena história da cirurgia cardíaca: e tudo aconteceu diante de nossos olhos. Rev Bras Cir Cardiovasc. 1999;14(3):177-84.

24. Dexter L, Haynes FW, Burwell CS, Eppinger EC, Sagerson RP Evans JM. Studies of congenital heart disease. II. The pressure and oxygen content of blood in the right auricle, right ventricle, and pulmonary artery in control patients, with observations on the oxygen saturation and source of pulmonary "capillary" blood. J Clin Invest. 1947;26(3):554-60.

25. Swan HJ, Ganz W, Forrester J, Marcus H, Diamond G, Chonette D. Catheterization of the heart in man with use of a flow-directed balloon-tipped catheter. N Engl J Med. 1970;283(9):447-51.

26. Bing RJ. Physiologic methods in the diagnosis of congenital heart disease. Surg Gynecol Obstet. 1949;88(3):399-401.

27. Pepine C, Hill J, Lambert C. Diagnostic and therapeutic cardiac catheterization. Baltimore: Williams \& Wilkins; 1997.

28. Bing R, Vandam L, Gregoire J, Handelsman W, Goodale W, Eckenhoff J. Catheterization of the coronary sinus and the middle cardiac vein in man. Proc Soc Exp Biol Med. 1947; 66:239-40.

29. Bing RJ, Hammond MM. The measurement of coronary blood flow, oxygen consumption, and efficiency of the left ventricle in man. Am Heart J. 1949;38(1):1-24.

30. Clark D. A history of cardiac catheterization. In: Clark D editor. Coronary angioplasty. $2^{\text {nd }}$ ed. New York: Wiley-Liss; 1991. p. 1-8.

31. dos Santos R, Lamas A, Pereira-Caldas J. Arteriografia da aorta e dos vasos abdominais. Med Contemp. 1929;47:93-7.

32. Robb G, Steinberg I. Visualization of the chambers of the heart, the pulmonary circulation, and the great blood vessels in man. A practical method. Am J Roentgenol. 1939; 41(1):1-17

33. Castellanos A, Pereira R. Counter-current aortography. Rev Cuban Cardiol. 1939;2:187. 
34. Fariñas P. A new technique for the arteriographic examination of the abdominal aorta and its branches. Am J Roentgenol. $1941 ; 46: 641-5$

35. Radner S. An attempt at the roentgenologic visualization of the coronary blood vessels in man. Acta Radiol (Diagn) (Stockh). 1945;26:497-502.

36. Radner S. Thoracal aortography by catheterization from the radial artery: preliminary report of a new technique. Acta Radiol. 1948;29(2):178-80.

37. Gonsson G. Visualization of the coronary arteries. Acta Radiol. 1948;29(6):536-40.

38. Ingraham F, Alexander E, Matson D. Polyethylene, a new synthetic plastic for use in surgery. Experimental applications in neurosurgery. JAMA. 1947;135:82-7.

39. Pierce EC $2^{\text {nd }}$. Percutaneous femoral artery catheterization in man with special reference to aortography. J Surg Gynecol Obstet. 1951;93(1):56-74

40. Seldinger SI. Catheter replacement of the needle in percutaneous arteriography; a new technique. Acta Radiol. 1953;39(5):368-76.

41. Odman P. Thoracic aortography by means of a radiopaque polythene catheter inserted percutaneously. Acta Radiol. 1956;45(23):117-24.

42. Limón Lason R, Alvarez V, Bouchard F. El cateterismo intracardiaco. Cateterizacion de las cavidades izquierdas en el hombre. Registro simultaneo de presión y electrocardiograma intracavitarios. Arch Inst Cardiol México. 1950; 20:271-85.

43. Reboul H, Racine M. La ventriculographie cardiaque expérimentale. Presse Med. 1933;37:763-7.

44. Dotter CT, Judkins MP. Transluminal treatment of arteriosclerotic obstruction. Description of a new technic and a preliminary report of its application. Circulation. 1964;30:654-70.

45. Ponsdomenech ER, Beato Nunez V. Heart puncture in man for diodrast visualization of the ventricular chambers and great arteries. Am Heart J. 1951;41(5):643-50.

46. Brock R, Milstein BB, Ross DN. Percutaneous left ventricular puncture in the assessment of aortic stenosis. Thorax. 1956; 11(3):163-71

47. Radner S. Suprasternal puncture of the left atrium for flow studies. Acta Med Scand. 1954;148(1):57-60.

48. Hansen AT, Fabricius J, Pedersen A, Sandoe E. Suprasternal puncture of the left atrium and great vessels. Experience from 500 punctures. Am Heart J. 1962;63:443-50.

49. Allison PR, Linden RJ. The bronchoscopic measurement of left auricular pressure. Circulation. 1953;7(5):669-73.

50. Facquet J, Alhomme $\mathrm{P}$, Lemoine JM, Colvez $\mathrm{P}$, Lagadoux. Left auricular pressure, obtained by transbronchial route, in mitral disorders. Arch Mal Coeur Vaiss. 1954;47(2):136-46.

51. Bjork VO, Malmstrom G, Uggla LG. Left auricular pressure measurements in man. Ann Surg. 1953;138(5):718-25.

52. Ross J Jr. Transeptal left heart catheterization: a new method of left atrial puncture. Ann Surg. 1959;149(3):395-401.

53. Prioton JB, Thevenet A, Pelissier $M$, Puech $P$, Latour $H$, Pourquier J. Left ventricular cardiography by femoral percutaneous retrograde catheterization; technic \& early results. Presse Med. 1957;65(86):1948-51.

54. Dotter CT, Gensini GG. Percutaneous retrograde catheterization of the left ventricle and systemic arteries of man. Radiology. 1960;75:171-84.

55. Tondreau RL. The retrospectoscope. Egas Moniz 18741955. Radiographics. 1985;5(6):994-7.

56. Kouwenhoven WB, Jude JR, Knickerbocker GG. Closedchest cardiac massage. JAMA. 1960;173:1064-7.
57. Zoll P, Linenthal A, Phelps M. Termination of refractory tachycardia by external electric countershock. Circulation. $1961 ; 24: 1078$.

58. Ferris L, King B, Spence P, Williams H. Effect of electric shock on the heart. Electric Engineering. 1936;55:498-515.

59. Wiggers $C$. The evolution of ventricular fibrillation. Am Heart J. 1940;20:399-412.

60. Lown B, Neuman J, Amarasingham R, Berkovits BV. Comparison of alternating current with direct electroshock across the closed chest. Am J Cardiol. 1962;10:223-33.

61. Littmann D, Starobin OE, Hall JH, Matthews RJ, Williams JA. A new method of left ventricular catheterization. Circulation. 1960;21:1150-5.

62. Bellman S, Frank HA, Lambert PB, Littmann D, Williams JA. Coronary arteriography. I. Differential opacification of the aortic stream by catheters of special design: experimental development. N Engl J Med. 1960;262:325-8.

63. Williams JA, Littmann D, Hall JH, Bellman S, Lambert PB, Frank HA. Coronary arteriography. II. Clinical experiences with the loop-end catheter. N Engl J Med. 1960;262:328-32.

64. Cope $C$. Technique for transseptal catheterization of the left atrium; preliminary report. J Thorac Surg. 1959;37(4):482-6.

65. Brockenbrough E, Braunwald E. A new technic for left ventricular angiocardiography and transseptal left heart catheterization. Am J Cardiol. 1960;6:1062-4.

66. Bevegard S, Carlens E, Jonsson B, Karlöf I. A technique for transseptal left heart catheterization via the right external jugular vein. Thorax. 1960;15:299-302.

67. Mullins C. New catheter and technique for transseptal left heart catheterization in infants and children. Circulation. 1979; 59/60(Supl II):II-251

68. Broden B, Jonsson G, Karnell J. Thoracic aortography; observations on technical problems connected with the method and various risks involved in its use. Acta Radiol. 1949;32(5-6):498-508.

69. Rousthöi P. Über angiokardiographie. Acta Radiol. 1933;14: 419-23.

70. Di Guglielmo L, Guttadauro M. Anatomic variations in the coronary arteries: an arteriographic study in living subjects. Acta Radiol. 1954;41(5):393-416.

71. Thal AP, Richards LS, Greenspan R, Murray MJ. Arteriographic studies of the coronary arteries in ischemic heart disease. J Am Med Assoc. 1958;168(16):2104-9.

72. Dotter CT, Frische LH. Visualization of the coronary circulation by occlusion aortography: a practical method. Radiology. 1958;71(4):502-24.

73. Sones F, Shirey E, Proudfit W, Westcott R. Cine-coronary arteriography. Circulation. 1959;20:773-4.

74. Sones FM Jr, Shirey EK. Cine coronary arteriography. Mod Concepts Cardiovasc Dis. 1962;31:735-8.

75. Sousa JE, Medina LV, Fontes VF. Cinecoronariografia seletiva. Arq Bras Cardiol. 1968;21(1):25-32.

76. Ricketts HJ, Abrams HL. Percutaneous selective coronary cine arteriography. JAMA. 1962;181:620-4.

77. Judkins MP. Selective coronary arteriography. I. A percutaneous transfemoral technic. Radiology. 1967;89(5):815-24.

78. Gidlund AS. A new apparatus for direct cineroentgenography. Acta Radiol. 1949;32(2-3):81-8.

79. Alcan KE, Stertzer SH, Wallsh E, DePasquale NP, Bruno MS. The role of intra-aortic balloon counterpulsation in patients undergoing percutaneous transluminal coronary angioplasty. Am Heart J. 1983;105(3):527-30.

80. Gensini G. Historical review. In: Coronary arteriography. New York: Futura Publishing; 1975. 
81. Bargeron LM Jr, Elliott LP, Soto B, Bream PR, Curry GC. Axial cineangiography in congenital heart disease. Section I. Concept, technical and anatomic considerations. Circulation. 1977;56(6):1075-83.

82. Aldridge HE, McLoughlin MJ, Taylor KW. Improved diagnosis in coronary cinearteriography with routine use of 110 degrees oblique views and cranial and caudal angulations. Comparison with standard transverse oblique views in 100 patients. Am J Cardiol. 1975;36(4):468-73.

83. Fegler G. Measurement of cardiac output in anaesthetized animals by a thermodilution method. Q J Exp Physiol Cogn Med Sci. 1954;39(3):153-64.

84. Gorlin R, Gorlin S. Hydraulic formula for calculation of the area of the stenotic mitral valve, other cardiac valves, and central circulatory shunts. I. Am Heart J. 1951;41(1):1-29.

85. Rashkind WJ, Miller WW. Creation of an atrial septal defect without thoracotomy. A palliative approach to complete transposition of the great arteries. JAMA. 1966;196(11):991-2.

86. Rashkind WJ, Miller WW. Transposition of the great arteries. Results of palliation by balloon atrioseptostomy in thirty-one infants. Circulation. 1968;38(3):453-62.

87. Park SC, Zuberbuhler JR, Neches WH, Lenox CC, Zoltun RA. A new atrial septostomy technique. Cathet Cardiovasc Diagn. 1975;1(2):195-201.

88. Sherlag BJ, Lau SH, Helfant RH, Berkowitz WD, Stein E, Damato AN. Catheter technique for recording His bundle activity in man. Circulation. 1969;39(1):13-8.

89. Robinson A, Snider I. Eletrofisiologia clínica, eletroterapia e teste eletrofisiológico. São Paulo: Artmed; 2002.

90. Chazov El, Matveeva LS, Mazaev AV, Sargin KE, Sadovskaia GV, Ruda MI. Intracoronary administration of fibrinolysin in acute myocardial infarct. Ter Arkh. 1976;48(4):8-19.

91. Rentrop P, De Vivie ER, Karsch KR, Kreuzer H. Acute coronary occlusion with impending infarction as an angiographic complication relieved by a guide-wire recanalization. Clin Cardiol. 1978;1(2):101-6.

92. Rentrop KP, Blanke $H$, Rarsch KR, Wiegand $V$, Köstering $H$, Oster $\mathrm{H}$, et al. Acute myocardial infarction: intracoronary application of nitroglycerin and streptokinase. Clin Cardiol. 1979;2(5):354-63.

93. Meyer J, Merx W, Schmitz H, Erbel R, Kiesslich T, Dörr R. Percutaneous transluminal coronary angioplasty immediately after intracoronary streptolysis of transmural myocardial infarction. Circulation. 1982;66(5):905-13.

94. Hartzler GO, Rutherford BD, McConahay DR, Johnson WL Jr, McCallister BD, Gura GM Jr, et al. Percutaneous transluminal coronary angioplasty with and without thrombolytic therapy for treatment of acute myocardial infarction. Am Heart J. 1983;106(5 Pt 1):965-73.

95. Kan JS, White RI Jr, Mitchell SE, Gardner TJ. Percutaneous balloon valvuloplasty: a new method for treating congenital pulmonary-valve stenosis. N Engl J Med. 1982;307(9):540-2.

96. Lababidi Z, Wu JR, Walls JT. Percutaneous balloon aortic valvuloplasty: results in 23 patients. Am J Cardiol. 1984; 53(1):194-7.

97. Cribier A, Letac B, Lancelin B, Guermonprez J, Traisnel G, Machecourt J, et al. Percutaneous balloon valvuloplasty for acquired aortic stenosis: preliminary immediate results of the french registry [abstract]. Circulation. 1986;74:Il-208.

98. Inoue K, Owaki T, Nakamura T, Kitamura F, Miyamoto N. Clinical application of transvenous mitral commissurotomy by a new balloon catheter. J Thorac Cardiovasc Surg. 1984;87(3):394-402.

99. Lock J, Khalilullah M, Shrivastava S, Bahl V, Keane JF. Percutaneous catheter commissurotomy in rheumatic mitral stenosis. N Engl J Med. 1985;313(24):1515-8.
100. Babic UU, Pejcic P, Djurisic Z, Vucinic M, Grujicic SM. Percutaneous transarterial balloon valvuloplasty for mitral valve stenosis. Am J Cardiol. 1986;57(13):1101-4.

101. Lock JE, Castaneda-Zuniga WR, Fuhrman BP, Bass JL. Balloon dilation angioplasty of hypoplastic and stenotic pulmonary arteries. Circulation. 1983;67(5):962-7.

102. Singer MI, Rowen M, Dorsey TJ. Transluminal aortic balloon angioplasty for coarctation of the aorta in the newborn. Am Heart J. 1982;103(1):131-2.

103. Lock JE, Bass JL, Amplatz K, Fuhrman BP, Castaneda-Zuniga W. Balloon dilation angioplasty of aortic coarctations in infants and children. Circulation. 1983;68(1):109-16.

104. Grüntzig A, Kuhlmann $U$, Vetter W, Lütolf $U$, Meier B, Siegenthaler W. Treatment of renovascular hypertension with percutaneous transluminal dilatation of a renal-artery stenosis. Lancet. 1978;1(8068):801-2.

105. Wiggli $U$, Gratzl O. Transluminal angioplasty of stenotic carotid arteries: case reports and protocol. AJNR Am J Neuroradiol. 1983;4(3):793-5

106. Grube E, Schuler G, Buellesfeld L, Gerckens U, Linke A Wenaweser $\mathrm{P}$, et al. Percutaneous aortic valve replacement for severe aortic stenosis in high-risk patients using the second- and current third-generation self-expanding CoreValve prosthesis: device success and 30-day clinical outcome. Am Coll Cardiol. 2007;50(1):69-76.

107. Sarmento-Leite R, Quadros AS, Prates PRL, Zanatta LG, Salgado Filho PA, Grando T, et al. Implante valvular aórtico percutâneo. Experiência inicial no sul do Brasil. Rev Bras Cardiol Invas. 2008;16(4):398-405.

108. Grüntzig A, Hopff H. Perkutane Rekanalisation chronischer arterieller Verschlüsse mit einen neuen Dilatationskatheter. Dtsch Med Wochenschr. 1974;99(49):2502-10.

109. Grüntzig A. Perkutane dilatation von coronarstenosen. Beschreibung eines neuen Kathetersystems. Klin Wschr. 1976;54(11):543-5.

110. Gruentzig A, Turina M, Schneider J. Experimental percutaneous dilatation of coronary artery stenosis. Circulation. $1976 ; 54: I 1-81$

111. Gruentzig A, Myler R, Hanna E, Turina M. Coronary transluminal angioplasty [abstract]. Circulation. 1977;55-56(Supl III):III-84.

112. Gruntzig A. Transluminal dilatation of coronary-artery stenosis. Lancet. 1978;1(8058):263.

113. Myler R, Gruentzig A, Stertzer S. Coronary angioplasty. In: Rapaport E, ed. Cardiology Update 1983. New York: Elsevier; 1983. p. 1-66.

114. Grüntzig AR, Senning A, Siegenthaler WE. Nonoperative dilatation of coronary-artery stenosis: percutaneous transluminal coronary angioplasty. N Engl J Med. 1979;301(2):61-8.

115. Topol E. Textbook of interventional cardiology. $5^{\text {th }}$ ed. Philadelphia: WB Saunders; 2007.

116. Kent KM, Bentivoglio LG, Block PC, Cowley MJ, Dorros G, Gosselin AJ, et al. Percutaneous transluminal coronary angioplasty: report from the Registry of the National Heart, Lung, and Blood Institute. Am J Cardiol. 1982;49(8):2001-20.

117. Castaneda-Zuniga WR, Formanek A, Tadavarthy M, Vlodaver Z, Edwards JE, Zollikofer C. The mechanism of balloon angioplasty. Radiology. 1980;135(3):565-71.

118. Gottschall CA, Miler VV, Yordi LM, Cardoso CR, Rodrigues LC. Detection of restenosis after percutaneous transluminal coronary angioplasty by an angiographic score. J Invasive Cardiol. 1998;10(1):1-11.

119. Gottschall CA, Quadros AS, Sarmento-Leite R. Predictive score for target vessel revascularization after bare metal coronary stenting. J Invasive Cardiol. 2006;18(1):22-6.

120. Galiano N, Macruz R, Arié S, Armelin E, Frack C, Pileggi $\mathrm{F}$, et al. Enfarte agudo do miocárdio e choque. Tratamento 
por recanalização arterial através do cateterismo cardíaco. Arq Bras Cardiol. 1972;25:197-204.

121. Costantini CR, Garcia LC, Garcia DP, Rojas R, Michelotto PV, Nogueira F. Angioplastia coronariana transluminal. Aspectos cineangiográficos e metabólicos. Relato de um caso. Arq Bras Cardiol. 1980;34(4):307-10.

122. Sousa JE, Büchler JR, Pimentel Filho WA, de Moraes AG. Angioplastia coronária transluminal percutânea. Arq Bras Cardiol. 1980;35(1):1-4.

123. Gottschall C (Presidente). Canela: V Congresso Brasileiro de Hemodinâmica e Angiocardiografia; 1980.

124. Gottschall C, Miler V, Arié S. Angioplastia coronariana transluminal percutânea (ACTP) em paciente com oclusão completa de artéria descendente anterior. São Paulo: VII Congresso Brasileiro de Hemodinâmica e Angiocardiografia; 1982. Anais do Congresso. p. 8.

125. Savage R, Hollman J, Gruentzig A, King III S, Douglas J, Tankersley R. Can percutaneous transluminal coronary angioplasty be performed in patients with total occlusion? Circulation. 1982;66(Suppl II):II-330.

126. Simpson JB, Baim DS, Robert EW, Harrison DC. A new catheter system for coronary angioplasty. Am J Cardiol. 1982;49(5):1216-22.

127. Detre K, Holubkov R, Kelsey S, Cowley M, Kent K, Williams $D$, et al. Percutaneous transluminal coronary angioplasty in 1985-1986 and 1977-1981. The National Heart, Lung, and Blood Institute Registry. N Engl J Med. 1988;318(5):265-70.

128. Hartzler GO, Rutherford BD, McConahay DR, Johnson WL, Giorgi LV. "High-risk" percutaneous transluminal coronary angioplasty. Am J Cardiol. 1988;61(14):33G-7G.

129. Gottschall CA. Insights into coronary restenosis: lessons for peripheral vessels? J Invasive Cardiol. 1998;10(8):515-20.

130. Simpson J, Johnson D, Thapliyal H, Marks D, Braden L. Transluminal atherectomy: a new approach to the treatment of atherosclerotic vascular disease. Circulation. 1985;72 (Suppl III):III-146.

131. Zacca NM, Raizner AE, Noon GP, Short D $3^{\text {rd }}$, Weilbaecher D, Gotto A Jr, et al. Treatment of symptomatic peripheral atherosclerotic disease with a rotational atherectomy device. Am J Cardiol. 1989;63(1):77-80.

132. Bertrand ME, Lablanche JM, Leroy F, Bauters C, De Jaegere $\mathrm{P}$, Serruys PW, et al. Percutaneous transluminal coronary rotary ablation with Rotablator (European experience). Am J Cardiol. 1992;69(5):470-4.

133. Baim DS, Cutlip DE, Sharma SK, Ho KK, Fortuna R, Schreiber $\mathrm{TL}$, et al. Final results of the Balloon vs Optimal Atherectomy Trial (BOAT). Circulation. 1998;97(4):322-31.

134. Ambrose JA, Winters SL, Stern A, Eng A, Teichholz LE, Gorlin R, et al. Angiographic morphology and the pathogenesis of unstable angina pectoris. J Am Coll Cardiol. 1985;5(3):609-16.

135. Ryan TJ, Faxon DP, Gunnar RM, Kennedy JW, King SB $3^{\text {rd }}$, Loop FD, et al. Guidelines for percutaneous transluminal coronary angioplasty. A report of the American College of Cardiology/American Heart Association Task Force on Assessment of Diagnostic and Therapeutic Cardiovascular Procedures (Subcommittee on Percutaneous Transluminal Coronary Angioplasty. Circulation. 1988;78(2):486-502.

136. Ryan T, Bauman W, Kennedy J, Kereiakes D, King III S, McCallister B, et al. ACC/AHA Guidelines for percutaneous transluminal coronary angioplasty. J Am Coll Cardiol. 1993; 22:2033-54.

137. Ellis SG, Vandormael MG, Cowley MJ, DiSciascio G, Deligonul U, Topol EJ, et al. Coronary morphologic and clinical determinants of procedural outcome with angioplasty for multivessel coronary disease. Implications for patient selection. Multivessel Angioplasty Prognosis Study Group. Circulation. 1990;82(4):1193-202.

138. Anderson HV, Roubin GS, Leimgruber PP, Cox WR, Douglas JS Jr, King SB $3^{\text {rd }}$, et al. Measurement of transestenotic pressure gradient during percutaneous transluminal coronary angioplasty. Circulation. 1986;73(6):1223-30.

139. Hodgson JM, Graham SP, Savakus AD, Dame SG, Stephens DN, Dhillon OS, et al. Clinical percutaneous imaging of coronary anatomy using an over-the-wire ultrasound catheter system. Int J Card Imaging. 1989;4(2-4):187-93.

140. Abizaid A, Mintz GS, Pichard AD, Kent KM, Satler LF, Walsh $\mathrm{CL}$, et al. Clinical, intravascular ultrasound, and quantitative angiographic determinants of the coronary flow reserve before and after percutaneous transluminal coronary angioplasty. Am J Cardiol. 1998;82(4):423-8.

141. Abizaid AS, Mintz GS, Mehran R, Abizaid A, Lansky AJ, Pichard AD, et al. Long-term follow-up after percutaneous transluminal coronary angioplasty was not performed based on intravascular ultrasound findings: importance of lumen dimensions. Circulation. 1999;100(3):256-61.

142. Abizaid AS, Mintz GS, Abizaid A, Mehran R, Lansky AJ, Pichard AD, et al. One-year follow-up after intravascular ultrasound assessment of moderate left main coronary artery disease in patients with ambiguous angiograms. J Am Coll Cardiol. 1999;34(3):707-15.

143. Stack RS, Quigley PJ, Collins G, Phillips HR $3^{\text {rd }}$. Perfusion balloon catheter. Am J Cardiol. 1988;61(14):77G-80G.

144. Hajduczki I, Kar S, Areeda J, Ryden L, Corday S, Haendchen $\mathrm{R}$, et al. Reversal of chronic regional myocardial dysfunction (hibernating myocardium) by synchronized diastolic coronary venous retroperfusion during coronary angioplasty. J Am Coll Cardiol. 1990;15(1):238-42.

145. Carrel A. Results of the permanent intubation of the thoracic aorta. Surg Gyn Obstet. 1912;15:245-8.

146. Dotter CT. Transluminally-placed coilspring endarterial tube grafts. Long-term patency in canine popliteal artery. Invest Radiol. 1969;4(5):329-32.

147. Dotter CT, Buschmann RW, McKinney MK, Rösch J. Transluminal expandable nitinol coil stent grafting: preliminary report. Radiology. 1983;147(1):259-60.

148. Cragg A, Lund G, Rysavy J, Castaneda F, Castaneda-Zuniga W, Amplatz K. Nonsurgical placement of arterial endoprotheses: a new technique using nitinol wire. Radiology. 1983; 147(1):261-3

149. Palmaz JC, Sibbitt RR, Reuter SR, Tio FO, Rice WJ. Expandable intraluminal graft: a preliminary study. Work in progress. Radiology. 1985;156(1):73-7.

150. Sigwart U, Puel J, Mirkovitch V, Joffre F, Kappenberger L. Intravascular stents to prevent occlusion and restenosis after transluminal angioplasty. N Engl J Med. 1987;316(12): 701-6.

151. Fischman DL, Leon MB, Baim DS, Schatz RA, Savage MP Penn I, et al. A randomized comparison of coronary-stent placement and balloon angioplasty in the treatment of coronary artery disease. Stent Restenosis Study Investigators. N Engl J Med. 1994;331(8):496-501.

152. George BS, Voorhees WD $3^{\text {rd }}$, Roubin GS, Fearnot NE, Pinkerton CA, Raizner AE. Multicenter investigation of coronary stenting to treat acute or threatened closure after percutaneous transluminal coronary angioplasty: clinical and angiographic outcomes. J Am Coll Cardiol. 1993;22(1):135-43.

153. Souza A, Feres F, Tanajura L. Experiência com o emprego do "stent" de Palmaz Schatz nas desobstruções das artérias coronárias. Arq Bras Cardiol. 1992;59(Supl 2):54. 
154. Serruys PW, de Jaegere P, Kiemeneij F, Macaya C, Rutsch W, Heyndrickx G, et al. A comparison of balloon-expandablestent implantation with balloon angioplasty in patients with coronary artery disease. Benestent Study Group. N Engl J Med. 1994;331(8):489-95.

155. Morice MC, Zemour G, Benveniste E, Biron Y, Bourdonnec C, Faivre R, et al. Intracoronary stenting without coumadin: one month results of a French multicenter study. Cathet Cardiovasc Diagn.1995;35(1):1-7.

156. Colombo A, Hall P, Nakamura S, Almagor Y, Maiello L, Martini $G$, et al. Intracoronary stenting without anticoagulation accomplished with intravascular ultrasound guidance. Circulation. 1995;91(6):1676-88.

157. Schömig A, Neumann $F$, Kastrati A, Schühlen $H$, Blasini $R$, Hadamitzky M, et al. A randomized comparison of antiplatelet and anticoagulant therapy after the placement of coronaryartery stents. N Engl J Med. 1996;334(17):1084-9.

158. Betriu A, Masotti M, Serra A, Alonso J, Fernández-Avilés F, Gimeno $F$, et al. Randomized comparison of coronary stent implantation and balloon angioplasty in the treatment of de novo coronary artery lesions (START): a four-year follow-up. J Am Coll Cardiol. 1999;34(5):1498-506.

159. Gottschall C, Quadros A, Sarmento-Leite R. É possível prever a reestenose após o implante de stents coronarianos convencionais? Proposta de um escore de risco baseado em variáveis obtidas antes do procedimento. Rev Bras Cardiol Invas. 2006;14(1):63-70.

160. Sousa JE, Costa MA, Abizaid A, Abizaid AS, Feres F, Pinto $\mathrm{IM}$, et al. Lack of neointimal proliferation after implantation of sirolimus-coated stents in human coronary arteries: a quantitative coronary angiography and three-dimensional intravascular ultrasound study. Circulation. 2001;103(2):192-5.
161. Holmes DR Jr, Leon MB, Moses JW, Popma JJ, Cutlip D, Fitzgerald PJ. Analysis of 1-year clinical outcomes in the SIRIUS trial: a randomized trial of a sirolimus-eluting stent versus a standard stent in patients at high risk for coronary restenosis. Circulation. 2004;109(5):634-40.

162. Nordmann A, Briel M, Bucher HC. Mortality in randomized controlled trials comparing drug-eluting vs. bare metal stents in coronary artery disease: a meta-analysis. Eur Heart J. 2006;27(23):2784-814.

163. Mauri L, Silbaugh TS, Wolf RE, Zelevinsky K, Lovett A, Zhou Z, et al. Long-term clinical outcomes after drugeluting and bare-metal stenting in Massachussetts. Circulation. 2008;118(18):1817-27.

164. Joner M, Finn AV, Farb A, Mont EK, Kolodgie FD, Ladich E, et al. Pathology of drug-eluting stents in humans: delayed healing and late thrombotic risk. J Am Coll Cardiol. 2006; 48(1):193-202.

165. Pfisterer M, Brunner-La Rocca HP, Buser PT, Rickenbacher $\mathrm{P}$, Hunziker $\mathrm{P}$, Mueller $\mathrm{C}$, et al; BASKET-LATE Investigators. Late clinical events after clopidogrel discontinuation may limit the benefit of drug-eluting stents: an observational study of drug-eluting versus bare-metal stents. J Am Coll Cardiol. 2006;48(12):2584-91.

166. Sociedade Brasileira de Cardiologia e Sociedade Brasileira de Hemodinâmica e Cardiologia Intervencionista. Diretrizes de intervenção coronária percutânea e métodos adjuntos diagnósticos em cardiologia intervencionista. Rev Bras Cardiol Invas. 2008;16(Supl 2):9-88.

Nota: Todos os títulos foram conferidos nas fontes. Eventuais diferenças de nomes refletem a grafia dos trabalhos originais. 